\title{
How to Regulate Bitcoin? \\ Decentralized Regulation for a Decentralized Cryptocurrency ${ }^{\dagger}$
}

\author{
Hossein Nabilou*
}

\begin{abstract}
Bitcoin is a distributed system. The greatest dilemma it poses to the current legal and regulatory systems is that it is hardly possible to regulate a distributed network in a centralized fashion as decentralized permissionless blockchain-based cryptocurrencies are antithetical to the existing centralized structure of monetary and financial regulation. By shifting the policy debate from whether to regulate bitcoin and other decentralized cryptocurrencies to how to regulate them, this paper proposes a more nuanced policy recommendation for regulatory intervention in the cryptocurrency ecosystem. This policy approach relies on a decentralized regulatory architecture that is built upon the existing regulatory infrastructure and makes use of the existing as well as the emerging middlemen in the industry. It argues that instead of regulating the technology or the cryptocurrencies at the code or protocol layer, which might not be desirable, even if feasible, the regulation should target the applications and use-cases of cryptocurrencies. Such a regulatory strategy can best be implemented through directing the edicts and interdictions of regulation towards the middlemen, and can be enforced by the existing financial market participants and traditional gatekeepers such as banks, payment service providers and exchanges, as well as new emerging participants, such as large and centralized node operators and miners that are likely to replicate the functions of the traditional gatekeepers.
\end{abstract}

Keywords: Cryptocurrency, Bitcoin, Money, Payment, Banking, Regulation, Decentralization

JEL classification: $E 42, E 51, E 58, G 01, G 23, G 28, K 22, K 23, K 24$

\footnotetext{
$\dagger$ The author is grateful to Prof. André Prüm for his insights, comments and feedback on the earlier drafts of some parts of this paper. All errors are those of the author.

* Postdoctoral researcher in Banking and Financial Law; University of Luxembourg; Faculty of Law, Economics and Finance; LL.M., University of Pennsylvania Law School; E-mail: hossein.nabilou@ uni.lu
} 


\section{Introduction}

A decade after the launch of the first cryptocurrency, regulators are waking up to the potential costs and benefits of this arguably transformative technology. Unlike most of the earlier innovations in financial technology (fintech), which focused on making marginal improvements in the financial system by improving market frictions, cryptocurrencies aim to bring about a paradigm shift in the monetary and financial systems by removing trust in third parties and replacing it with cryptographic proof. ${ }^{1}$ Despite ebbs and flows, and peaks and troughs, Bitcoin has managed to achieve relative success in placing itself as a store of value - despite being a volatile one - and a niche medium of exchange in a relatively short period of time. ${ }^{2}$

In the banking and monetary systems, cryptocurrencies' promise of decentralization is to be achieved by disintermediating middlemen that used to be gatekeepers in the financial markets, such as banks and a chain of intermediaries in the cross-border fund transfer business (e.g., correspondent banking and remittances). ${ }^{3}$ This disintermediation poses a specific challenge to the regulation of cryptocurrencies as the traditional methods of financial regulation are mainly reliant on either the direct regulation of activities, entities, and instruments or the regulation of the middlemen and gatekeepers. However, despite achieving certain degrees of disintermediation and the reduced role of intermediaries in payments and a number of other financial transactions, cryptocurrencies have created various forms of new middlemen. This provides new opportunities for financial regulators to focus on these new intermediaries to regulate cryptocurrencies. This paper highlights the role of these middlemen and will argue that the regulatory focus should be shifted from regulating the protocol or outright interdictions placed on cryptocurrency transactions, which could have several unintended consequences, to regulating those middlemen who will most likely take the role of new gatekeepers. This model of regulation is more likely to be successful in addressing the emerging risks of cryptocurrencies.

As bitcoin and other decentralized cryptocurrencies are open-source protocols, the regulation should not target them as there are several practical impediments for regulation of decentralized open-source technologies that would render their centralized direct regulation infeasible. This means that the traditional approach to regulation, which is mainly built on centralized command-and-control techniques may not be a successful regulatory strategy when it comes to regulating decentralized cryptocurrencies. Instead, it seems that the interface between the real and the virtual or the interface between the financial institutions and cryptocurrencies should be the target at which the regulation is

\footnotetext{
${ }^{1}$ Satoshi Nakamoto, "Bitcoin: A Peer-to-Peer Electronic Cash System," (2008). For the importance of bitcoin and how it fits within and differs from other types of money in the financial system, see Hossein Nabilou and André Prüm, "Ignorance, Debt and Cryptocurrencies: The Old and the New in the Law and Economics of Concurrent Currencies," Journal of Financial Regulation 5, no. 1 (2019).

${ }^{2}$ However, the jury is still out on the success or failure of such a grand ambition.

${ }^{3}$ For the instances of failure of gatekeepers in conducting their semi-regulatory functions, see Jennifer Payne, "The Role of Gatekeepers," in The Oxford Handbook of Financial Regulation, ed. Niamh Moloney, Eilís Ferran, and Jennifer Payne (Oxford: Oxford University Press, 2015).
} 
aimed. Within this decentralized approach, it is of utmost importance to focus on the incentives of the participants in both the cryptocurrency ecosystem and the banking and financial system and deploy mechanisms that are incentive-compatible and capture resistant.

This paper sheds some light on the legal and regulatory aspects of cryptocurrency ecosystems and provides a conceptual framework for analyzing and deploying the future regulation of cryptocurrencies. The paper proceeds as follows. The first section illustrates the conceptual differences between centralized direct regulation and decentralized indirect regulation of cryptocurrencies. Second, the paper will spell out the limitations and potential drawbacks of the direct and centralized regulation of cryptocurrencies. Third, the paper turns to searching for a cogent, coherent and more importantly feasible approach by relying on methods for regulating cryptocurrencies in a decentralized fashion through banks and payment systems. Finally, the paper closes with concluding remarks.

This paper studies the regulation of cryptocurrencies, in particular, bitcoin, within the current monetary, banking and financial regulatory framework from a financial law or law-and-finance perspective. The literature on law and technology will be used only to the extent necessary to serve the objectives of the paper.

\section{In search of a coherent regulatory strategy}

In the tradition of the classic rationale for regulation, which is based on market failure, the regulation of cryptocurrencies would begin where the market fails. ${ }^{4}$ Among different sources of market failure, modern regulation of banking and finance puts special emphasis on the regulation of potential externalities of financial activities and mainly focuses on risk-based regulation that tends to minimize the potential risks or externalities. Within the cryptocurrency ecosystem, it appears that a great majority of externalities of cryptocurrencies emerge where they interact with the real world. For example, such

\footnotetext{
${ }^{44}$ Although this paper finds several instances of market failures, even in the absence of market failures, there would be a need for regulatory intervention to facilitate the evolution of the cryptocurrency ecosystem through standardization and perhaps requirements for interoperability and open Application Programming Interfaces (APIs) - a design-based regulatory intervention - as adopted in the Directive (EU) 2015/2366 of the European Parliament and of the Council of 25 November 2015 on payment services in the internal market, amending Directives 2002/65/EC, 2009/110/EC and 2013/36/EU and Regulation (EU) No 1093/2010, and repealing Directive 2007/64/EC, OJ L 337, 23.12.2015 (Also known as the Payment Services Directive or PSD2).
} 
risks include concerns about fraud ${ }^{5}$ market manipulation, ${ }^{6}$ financial crime, ${ }^{7}$ consumer protection, ${ }^{8}$ liability issues in distributed ledgers, ${ }^{9}$ the development of large closed networks that can potentially create barriers to entry, ${ }^{10}$ concerns about taxation policy for cryptocurrencies,,${ }^{11}$ monetary policy, ${ }^{12}$ and financial stability. ${ }^{13}$ Further risks may arise from the lack of common standards and interoperability, governance issues,${ }^{14}$ privacy concerns, ${ }^{15}$ scalability, ${ }^{16}$ and potential risks in the issuance of central bank digital currency (CBDC) or digital base money (DBM). ${ }^{17}$ As the nature of these risks suggests, they arise from the interactions between the virtual and the real. As such an interaction is often made possible by a new class of emerging middlemen, the regulation can minimize risks by focusing on the middlemen who facilitate the interaction between the real economy and the cryptocurrency markets.

Such multi-faceted challenges, coupled with cryptocurrencies' price volatility and their hybrid nature, which allows them to be used as a means of payment, ${ }^{18}$ investment, ${ }^{19}$ and access, ${ }^{20}$ have led to a surge of interest in studying the potential venues for regulating cryptocurrencies among regulators ranging from financial crime enforcement agencies to banking, securities and commodity markets regulators. ${ }^{21}$ However, these studies were mainly concerned with initial coin offerings (ICOs) enabled by the

\footnotetext{
${ }^{5}$ Massimo Bartoletti et al., "Dissecting Ponzi Schemes on Ethereum: Identification, Analysis, and Impact," (2017).; Financial Stability Oversight Council, "Financial Stability Oversight Council (Fsoc) 2016 Annual Report," (Washington, D.C.: Financial Stability Oversight Council, 2016), 127.

6 Anonymous (32E3690D50B3B477DF7841212D4BB938DC9CDB50307618328E7F8B53F37CC1E2), "Quantifying the Effect of Tether," (January 24, 2018).; John M Griffin and Amin Shams, "Is Bitcoin Really Un-Tethered?," SSRN Working Paper Series (2018).

7 Kim-Kwang Raymond Choo, "Cryptocurrency and Virtual Currency: Corruption and Money Laundering/Terrorism Financing Risks?," in Handbook of Digital Currency: Bitcoin, Innovation, Financial Instruments, and Big Data, ed. David Lee Kuo Chuen (San Diego, CA: Academic Press, 2015).; Robert Stokes, "Virtual Money Laundering: The Case of Bitcoin and the Linden Dollar," Information \& Communications Technology Law 21, no. 3 (2012). See also Office of the New York State Attorney General, "Virtual Markets Integrity Initiative Report," (September 18, 2018).

${ }^{8}$ Dong He et al., "Virtual Currencies and Beyond: Initial Considerations," (Washington, D.C.: International Monetary Fund, 2016), 28-29.

${ }^{9}$ Dirk A Zetzsche, Ross P Buckley, and Douglas W Arner, "The Distributed Liability of Distributed Ledgers: Legal Risks of Blockchain," University of Illinois Law Review (forthcoming) (2017).

${ }^{10}$ Dong He et al., "Fintech and Financial Services: Initial Considerations," IMF Staff Discussion Note SDN/17/05 (2017).

${ }^{11}$ Aleksandra Bal, "How to Tax Bitcoin?," in Handbook of Digital Currency: Bitcoin, Innovation, Financial Instruments, and Big Data, ed. David Lee Kuo Chuen (San Diego, CA: Academic Press, 2015).

${ }^{12}$ Christine Lagarde, "Central Banking and Fintech - a Brave New World?," Bank of England conference, London (September 29, 2017).

${ }^{13}$ Committee on Payments and Market Infrastructures, "Digital Currencies," (Basel: Bank for International Settlements, 2015), 15-16.; Financial Stability Board, "Crypto-Asset Markets: Potential Channels for Future Financial Stability Implications," (Basel: Financial Stability Board, 10 October 2018).

${ }^{14}$ Aaron van Wirdum, "A Primer on Bitcoin Governance, or Why Developers Aren't in Charge of the Protocol," Bitcoin MagazineSept. 7, 2016.

${ }^{15}$ Primavera De Filippi, "The Interplay between Decentralization and Privacy: The Case of Blockchain Technologies," (2016).

${ }^{16}$ European Securities and Markets Authority, "The Distributed Ledger Technology Applied to Securities Markets," (Paris: European Securities and Markets Authority, 2017), 2. See also Huw Van Steenis et al., "Global Insight: Blockchain in Banking: Disruptive Threat or Tool?," in Morgan Stanley Research Report (New York: Morgan Stanely, 2016).

17 See Hossein Nabilou, "Central Bank Digital Currencies: Preliminary Legal Observations," SSRN Working Paper Series (2019).; Yves Mersch, "Digital Base Money: An Assessment from the Ecb's Perspective," in Speech at the Farewell ceremony for Pentti Hakkarainen, Deputy Governor of Suomen Pankki - Finlands Bank, Helsinki (16 January 2017).; Aleksander Berentsen and Fabian Schar, "The Case for Central Bank Electronic Money and the Non-Case for Central Bank Cryptocurrencies," Federal Reserve Bank of St. Louis Review (2018).; Morgan Ricks, "Money as Infrastructure," Vanderbilt Law Research Paper No. 17-63 (2018).

${ }^{18}$ Primarily known as 'cryptocurrencies'

${ }^{19}$ Also known as 'security tokens'

${ }^{20}$ Also known as 'utility tokens'

${ }^{21}$ European Securities and Markets Authority, "The Distributed Ledger Technology Applied to Securities Markets."
} 
distributed ledger technologies (DLTs), blockchain and cryptocurrencies ${ }^{22}$ and potential risks and rewards of the blockchain technology. Several studies by the European Central Bank (ECB), ${ }^{23}$ the European Banking Authority (EBA), ${ }^{24}$ the International Monetary Fund (IMF), ${ }^{25}$ the Bank for International Settlements (BIS), ${ }^{26}$ the US Federal Reserve and its regional banks ${ }^{27}$ about the costs and benefits of cryptocurrencies have been conducted. In addition, there is a burgeoning literature on the economic, monetary and financial aspects of cryptocurrencies as they relate to central bank digital currencies. ${ }^{28}$ Nevertheless, the legal aspects of cryptocurrencies and in particular the debate about how to regulate decentralized cryptocurrencies remain under-investigated. This paper is an attempt to narrow this gap.

As of this writing, due to the complexities and uncertainties as to the possible future developments of evolving cryptocurrency ecosystems, policymakers and regulators of major jurisdictions have taken a relatively hands-off, wait-and-see approach to regulating such currencies. Where regulators erred on the side of banning or bashing cryptocurrencies, they have faced classical problems of regulatory competition and regulatory arbitrage, i.e., the migration of the industry from their jurisdiction to more welcoming ones or migration of activities to underground or black markets.

\footnotetext{
${ }^{22}$ European Securities and Markets Authority, "Advice: Initial Coin Offerings and Crypto-Assets," (9 January 2019).

${ }^{23}$ European Central Bank, "Virtual Currency Schemes," (Frankfurt an Main: European Central Bank, October 2012).; European Central Bank, "Virtual Currency Schemes- a Further Analysis," (2015).; European Central Bank, "The Potential Impact of Dlts on Securities Post-Trading Harmonisation and on the Wider Eu Financial Market Integration," (Frankfurt am MainSeptember 2017); Andrea Pinna and Wiebe Ruttenberg, "Distributed Ledger Technologies in Securities Post-Trading: Revolution or Evolution?," ECB Occasional Paper Series No 172 (2016).

${ }^{24}$ European Banking Authority, "Eba Opinion on 'Virtual Currencies'," (London: European Banking Authority, 4 July 2014).; European Banking Authority, "Report with Advice for the European Commission on Crypto-Assets," (9 January 2019).

${ }^{25}$ Dong He et al., "Virtual Currencies and Beyond: Initial Considerations."; Tommaso Mancini-Griffoli et al., "Casting Light on Central Bank Digital Currency," IMF Staff Discussion Note No. 18/08 (2018).

${ }^{26}$ Morten Bech and Rodney Grarratt, "Central Bank Cryptocurrencies," BIS Quarterly Review (2017).; Committee on Payments and Market Infrastructures, "Digital Currencies."; Bank for International Settlements, "Cryptocurrencies: Looking Beyond the Hype," in Annual Economic Report (Basel2018).; Christian Barontini and Henry Holden, "Proceeding with Caution - a Survey of Central Bank Digital Currency," BIS Papers No 101 (January 2019).; Raphael Auer, "Beyond the Doomsday Economics of "Proof-of-Work" in Cryptocurrencies," BIS Working Papers No 765 (2019).

${ }^{27}$ Gina C. Pieters, "The Potential Impact of Decentralized Virtual Currency on Monetary Policy," Federal Reserve Bank of Dallas Globalization and Monetary Policy Institute 2016 Annual Report (2017).; Alexander Kroeger and Asani Sarkar to Federal Reserve Bank of New York Liberty Street Economics, June 27, 2017, 2016, http://libertystreeteconomics.newyorkfed.org/2016/03/is-bitcoin-really-frictionless.html.; Aleksander Berentsen and Fabian Schär, "A Short Introduction to the World of Cryptocurrencies," Federal Reserve Bank of St. Louis Review 100, no. 1 (First Quarter 2018).; Aleksander Berentsen and Fabian Schar, "The Case for Central Bank Electronic Money and the Non-Case for Central Bank Cryptocurrencies."; David Mills et al., "Distributed Ledger Technology in Payments, Clearing, and Settlement," Finance and Economics Discussion Series Divisions of Research \& Statistics and Monetary Affairs, Federal Reserve Board (2016).

${ }^{28}$ JP Koning, "Fedcoin," Moneyness April 11, 2018 (October 19, 2014); David Andolfatto, "Fedcoin: On the Desirability of a Government Cryptocurrency," MacroMania 2018 (February 03, 2015).; Sahil Gupta, Patrick Lauppe, and Shreyas Ravishankar, "Fedcoin: A Blockchain-Backed Central Bank Cryptocurrency," (2017).; Morten Bech and Rodney Grarratt, "Central Bank Cryptocurrencies."; Michael Kumhof and Clare Noone, "Central Bank Digital Currencies — Design Principles and Balance Sheet Implications," Bank of England Staff Working Paper No. 725 (2018).; John Barrdear and Michael Kumhof, "The Macroeconomics of Central Bank Issued Digital Currencies," Bank of England Staff Working Paper No. 605 (2016).; Michael D Bordo and Andrew T Levin, "Central Bank Digital Currency and the Future of Monetary Policy," (National Bureau of Economic Research, 2017).; Aleksander Berentsen and Fabian Schar, "The Case for Central Bank Electronic Money and the Non-Case for Central Bank Cryptocurrencies."; Eswar Prasad, "Central Banking in a Digital Age: Stock-Taking and Preliminary Thoughts," Hutchins Center on Fiscal \& Monetary Policy at Brookings (April 2018).; Larry White, "The World's First Central Bank Electronic Money Has Come - and Gone: Ecuador, 2014-2018," Alt-M: Ideas for an Alternative Monetary Future (March 29, 2018).
} 
It seems that such sporadic regulatory efforts have at best been counterproductive and there is a need for a more systematic regulatory approach to minimizing the risks of such decentralized cryptocurrencies, where the market fails to do so. To address market failures or effect behavioral changes in the objects of regulation in the financial markets, aside from harnessing self-regulatory mechanisms by making use of financial market participants, regulators often employ two overarching regulatory instruments: command-and-control instruments and economic instruments. Command-andcontrol instruments are the most traditional and intrusive method of effecting a behavioral change in the subjects of regulation. A command is 'an order backed by threats', ${ }^{29}$ the non-compliance or violation of which triggers coercive sanctions by the state. In this method of regulation, the law uses its traditional aspect through rules to pursue certain policy objectives. Command-and-control techniques often rely on direct regulation approach. Direct regulation refers to regulatory measures focusing immediately on the regulation of the industry itself as a discrete activity ${ }^{30}$ or on the activities immediately performed by business entities, targeting the industry's structure, strategies, and operations. Accordingly, the direct regulation of cryptocurrencies would involve regulating the code or protocol (i.e., design-based regulation), developers, ${ }^{31}$ the design features of the blockchain itself, wallet providers, node operators, miners, and users, or engaging in legislation and rule making that govern white papers.

In contrast, indirect regulation constitutes "market discipline-inspired regulatory measures largely targeting the creditors and counterparties" of those entities. ${ }^{32}$ It often utilizes an intermediary to transmit the imperatives or commands to the (primarily intended) regulated entity or activity that is the ultimate target. ${ }^{33}$ Indirect regulation is often viewed as a more efficient strategy in financial regulation in the presence of suitable 'surrogate regulators'. ${ }^{34}$ For example, regulation of exchanges, where cryptocurrencies are exchanged for fiat money, custodians and other service providers, such as merchant acceptance facilities and in some instances, wallet providers, would belong to the realm of indirect regulation. This paper advocates an indirect regulatory approach to regulating cryptocurrencies that relies on economic instruments. As will be demonstrated in the paper, such a regulatory approach would harbinger certain degrees of decentralization in addressing the challenges of cryptocurrencies.

\footnotetext{
${ }^{29}$ See: H. L. A. Hart, The Concept of Law, vol. 2 (New York: Oxford University Press, 1994), 16. For a classic definition of the command which Hart bases his attack on the account of law based on that definition, see John Austin, The Province of Jurisprudence Determined (New York: Cambridge University Press, 2001), 18-37.

${ }^{30}$ Phoebus Athanassiou, Hedge Fund Regulation in the European Union: Current Trends and Future Prospects (Alphen aan den Rijn (The Netherlands): Kluwer Law International, 2009), 227. For the application of the concept of direct and indirect regulation in the regulation of the hedge fund industry, see Hossein Nabilou and Alessio M. Pacces, "The Hedge Fund Regulation Dilemma: Direct Vs. Indirect Regulation," William \& Mary Business Law Review 6, no. I (2015).

31 Angela Walch, "In Code(Rs) We Trust: Software Developers as Fiduciaries in Public Blockchains," in Regulating Blockchain: Techno-Social and Legal Challenges, ed. Philipp Hacker, et al. (Oxford: Oxford University Press, Forthcoming 2019). For an different view, see: Aaron van Wirdum, "A Primer on Bitcoin Governance, or Why Developers Aren't in Charge of the Protocol," BITCOINMAGAZINESept. 7, 2016.; Jerry Brito and Peter van Valkenburgh, "Writing and Publishing Code Alone Cannot Be a Crime," CoinCenter.org (Octover 29, 2018).

${ }^{32}$ Phoebus Athanassiou, Hedge Fund Regulation in the European Union: Current Trends and Future Prospects, 227.

${ }^{33}$ Ibid., 227-28 \& 34.

${ }^{34}$ Hossein Nabilou and Alessio M. Pacces, "The Hedge Fund Regulation Dilemma: Direct Vs. Indirect Regulation."
} 


\section{Centralized direct regulation}

For tokens issued on permissioned or restricted distributed ledgers, the regulation would be straightforward, as it can target the proprietors of the ledger or the nodes with the access to and the authority of validating it. For centralized cryptocurrencies, relying on direct regulation using commandand-control techniques would be successful in achieving regulatory objectives. Such techniques may include mandatory creation of a scheme governance authority (body), Information Technology (IT) security requirements, and requirements on transaction verification process (e.g., the number of nodes and miners and confirmations needed for the finality of a transaction on the blockchain) can be imposed by law to be built into the design of a given cryptocurrency. Operational and business continuity requirements, requirements such as investor or user vetting process or customer due diligence before making the wallet or coin available to the user can be imposed directly on these identifiable scheme authorities. Therefore, centralized cryptocurrencies would not necessarily require any reorganization in the structure of financial regulation.

Another example of direct regulation of the cryptocurrency markets may involve central banking. Such direct involvement by central banks may be due to the concerns about potential impairment of the unit of account (i.e., central banks' monopoly over issuing banknotes), price stability or their mandate in implementing monetary policy. An example of this type of intervention may include banning cryptocurrency exchanges, financial institutions, and payment processors from handling or dealing in cryptocurrencies by central banks or other competent authorities. ${ }^{35}$ On the other extreme of the spectrum, the central bankers may be given the power to hold cryptocurrencies. For example, in the case of the ECB, this can be done as part of its tasks under conducting foreign-exchange operations or holding and managing the official foreign reserves of the Member States. As the ECB and NCBs can "acquire and sell spot and forward all types of foreign exchange assets and precious metals", ${ }^{36}$ and as 'foreign exchange assets' include "securities and all other assets in the currency of any country or units of account and in whatever form held", ${ }^{37}$ it would be difficult to argue that the ECB would not have the power to acquire and hold cryptocurrencies if need be.

Alternatively, a centralized direct regulation approach can rely on economic instruments. Economic instruments are regulatory tools and techniques that are designed to harness market discipline and to achieve behavioral changes or policy objectives by making use of the competitive forces and 'financial self-interests of market actors' ${ }^{38}$ Examples of such instruments are charges (fines), taxes, subsidies,

\footnotetext{
35 Global Legal Research Directorate Staff of the Library of Congress, "Regulation of Cryptocurrency in Selected Jurisdictions," (Washington D.C.,: The Law Library of Congress, June 2018). See China entry by Laney Zhang.

${ }^{36}$ Art. 23 the Protocol (no 4) on the Statute of the European System of Central Banks and of the European Central Bank (hereinafter, ESCB/ECB Statute).

${ }^{37}$ Art. 23 ESCB/ECB Statute

${ }^{38}$ Bronwen Morgan and Karen Yeung, An Introduction to Law and Regulation: Texts and Materials (New York: Cambridge University Press, 2007), 315.
} 
tradable permits, changes in liability rules and property rights. ${ }^{39}$ For example, designating cryptocurrencies as property for tax purposes and imposing property taxes each time a bitcoin or a fraction of it changes hands is an economic instrument that could severely stifle bitcoin adoption as a medium of exchange.

An additional tool for direct regulation of cryptocurrencies may be the design-based regulation ${ }^{40}$ Design-based regulation has historically been one of the main regulatory measures in regulating financial markets. ${ }^{41}$ In contrast to other modalities of regulation, ${ }^{42}$ which rely on rational human reasoning, design-based regulation seeks to "eliminate undesirable behaviour by designing out the possibility for its occurrence." The objective is to remove the possibility of non-compliance by eliminating the possibility for the application of human discretion in its entirety. ${ }^{43}$ This approach has a variety of applications in the regulation of cyberspace. In this perspective, the code is the architectural alternative for the deployment of legal rules. ${ }^{44}$ In other words, design-based regulation creates "a 'structure' that will organize, constrain and channel activity." 45

The difference between legal codes and computer codes is that legal codes are extrinsic. Namely, these codes can easily be breached, however, the consequences of such a breach is the sanction that ensures the compliance ex-post. However, the technical codes or computer codes are intrinsic, namely, in case of the violation of such rules, no further activities would be possible. ${ }^{46}$ In other words, the code selfenforces the protocols set by the code. For example, in smart contracts, the contract design accumulates

\footnotetext{
${ }^{39}$ Ibid., 85. Economic instruments, are classified into four main regulatory modalities; competition, consensus, communication and code (or architecture) according to the underlying 'modality' of control through which the behavior of regulated entities is shaped. Ibid., $9 \& 80$. Except code or architecture other regulatory modalities often rely on the economic instruments and use indirect regulation to achieve their objectives.

${ }^{40}$ Design-based regulation is also called structural regulation, code-based or architecture-based regulation and sometimes techno-regulation.

${ }^{41}$ See Hossein Nabilou, "Bank Proprietary Trading and Investment in Private Funds: Is the Volcker Rule a Panacea or yet Another Maginot Line?," Banking and Finance Law Review 32, no. 2 (2017).

${ }^{42}$ For a discussion of such modalities, see Bronwen Morgan and Karen Yeung, An Introduction to Law and Regulation: Texts and Materials, $9 \& 80$.

${ }^{43}$ Ibid., 102. Although in the eyes of some authors it seems that the design-based regulation has the promise of one hundred percent effectiveness, going as far as arguing that the "[1]aw as code is a start to the perfect technology of justice". (Lawrence Lessig, "The Zones of Cyberspace," Stanford Law Review 48 (1996): 1408.), Others identify certain reasons for the failure of such mechanisms. Particularly, Yeung argues that " $[\mathrm{t}]$ hose which operate by promoting behavioural change, or seek to change the impact of existing behaviour, are more vulnerable to failure than those which do not. And those which override individual behaviour are the most effective of all." See Karen Yeung, "Towards an Understanding of Regulation by Design," in Regulating Technologies: Legal Futures, Regulatory Frames and Technological Fixes, ed. Roger Brownsword and Karen Yeung (Portland, Oregon: Hart Publishing, 2008), 80 \& 106.

${ }^{44}$ Lawrence Lessig, Code: And Other Laws of Cyberspace (New York: Basic Books, 1999). Examples of design-based rules abound. Benthamite panopticon is one of the earliest examples of the use of design-based techniques in law enforcement. See Michel Foucault, Discipline and Punish: The Birth of the Prison (New Yrok: Vintage Books, 1995), 195-228. The ubiquitous use of speed humps is another example. The idea of separation of powers (See John C. Coates IV, "The Volcker Rule as Structural Law: Implications for Cost-Benefit Analysis and Administrative Law," Capital Markets Law Journal 10, no. 4 (2015): 449.) and even locating constitutional courts away from the seat of the legislative and the executive branches of government in some European countries with the aim of ensuring judicial independence is another example of design-based regulation. See Lawrence Lessig, Code: Version 2.0 (New York: Basic Books, 2006), 127-28.

45 John C. Coates IV, "The Volcker Rule as Structural Law: Implications for Cost-Benefit Analysis and Administrative Law," 448 .

${ }^{46}$ Peter Yeoh, "Regulatory Issues in Blockchain Technology," Journal of Financial Regulation and Compliance 25, no. 2 (2017): 200.
} 
the legislation, enforcement, and adjudication at one stage under the control of the coder that eliminates the possibility of a breach, hence dispensing with further stages that are to ensure compliance. ${ }^{47}$

Crafting design-based regulation in the cryptocurrency ecosystem cannot be independent of the specific features of the cryptocurrency in question and its underlying blockchain. For example, cryptocurrencies based on an unrestricted (permissionless) blockchain are to be treated differently from those built on a restricted (permissioned) blockchain with identifiable and relatively centralized nodes. In the same vein, centralized cryptocurrency schemes should be treated differently from decentralized ones such as bitcoin. Given the number and variety of cryptocurrencies, designing tailor-made regulations for such currencies would prove to be an insurmountable barrier for regulators and would render it dysfunctional.

Within the direct regulatory approach, to increase the efficiency of regulation, regulators can also consider a laddered approach to regulating cryptocurrencies. For example, thus far, regulatory intervention in cryptocurrency markets has been limited to moral suasion, i.e., using information provision to users and investors to raise awareness of the risks of cryptocurrencies, such as issuing public warnings and publishing research papers. Another manifestation of the laddered approach would be to focus on the market capitalization of cryptocurrencies and directly regulating the ones that pass certain thresholds in terms of size. In its extreme, the regulator would ban cryptocurrencies by imposing a ban on the use of cryptocurrency schemes and imposing a fine on cryptocurrency-based financial activities, exchanges or acceptance facilities. ${ }^{48}$

The greatest challenge to the direct regulation of cryptocurrencies lies in the fact that some of the largest cryptocurrencies are decentralized and designed to be censorship-resistant. In the absence of a centralized governance scheme, it is hard to propose a direct regulatory approach to regulating decentralized cryptocurrencies. ${ }^{49}$ The closest that regulation can get in regulating such cryptocurrencies is regulating miners, and perhaps relatively centralized nodes on the Lightning Network. ${ }^{50}$ However, given the geographic distribution of the miners and nodes in the decentralized network, such a regulatory approach would face barriers that could be hard to overcome. Therefore, the regulation would better focus on the applications, use-cases, and businesses that are being developed around these open source cryptocurrency protocols. ${ }^{51}$ As the second-layer solutions are being developed, it is reasonable

\footnotetext{
${ }^{47}$ However, economists typically view the law as a set of official prices. See: Robert Cooter, "Prices and Sanctions," Columbia law review 84, no. 6 (1984). In this sense, the application of smart contracts would not be optimal in all contractual relationships, as they eliminate the opportunity for negotiations in cases of (efficient) breaches.

${ }^{48}$ Daniel Broby and Samuel Baker, "Central Banks and Cryptocurrencies," Centre for Financial Regulation and Innovation White Paper (2018): 11.

${ }^{49}$ Yves Mersch, "Virtual Currencies Ante Portas," Speech at the 39th meeting of the Governor's Club Bodrum, Turkey, 14 May 2018 (14 May 2018).

${ }^{50}$ Joseph Poon and Thaddeus Dryja, "The Bitcoin Lightning Network: Scalable Off-Chain Instant Payments," (2016).

${ }^{51}$ For similar ideas see: Michèle Finck, "Blockchains: Regulating the Unknown," German Law Journal 19, no. 4 (2018): 689.; Julie Maupin, "Mapping the Global Legal Landscape of Blockchain and Other Distributed Ledger Technologies," Centre for International Governance Innovation Papaers No. 149 (2017).

There are improvements on Bitcoin protocol and also second layer solutions that promise to make bitcoin useful for all the above-mentioned purposes. For an overview of two such business improvements called "market exchange pricing", and "instantaneous exchange facilities", see William Luther and Lawrence White, "Can Bitcoin Become a Major Currency?," JMU
} 
to expect business communities being developed around them which could be directly identifiable and targeted by regulators.

However, this is not to say that direct regulation of cryptocurrencies would be completely ineffective. Although governments can hardly do away with decentralized cryptocurrencies, they can disrupt their growth. As with all currencies, the success of any currency depends on its widespread adoption, which entails network effects. Putting a ban on cryptocurrencies by governments can severely undermine their network effects. ${ }^{52}$ In addition, aggressive tax policy as part of the direct economic instruments, such as designating bitcoin as property for tax purposes and imposing property taxes each time a bitcoin or a fraction of it changes hands, as is being practiced in some jurisdictions, would severely stifle its adoption as a medium of exchange. However, the problem with a hard-touch regulatory approach is regulatory arbitrage. First, due to the distributed nature of bitcoin, no government can entirely and effectively ban or tax bitcoin away. And it is likely that a legal interdiction will only push bitcoin transactions to the darker corners of finance. Second, if only a few jurisdictions allow bitcoin transactions, such a ban would become ineffective because of regulatory arbitrage.

This paper argues that the best strategy for regulating cryptocurrencies is an indirect approach that makes use of economic instruments. After studying the impediments to the direct regulation of cryptocurrencies, the paper turns to the promises of the decentralized indirect regulation in the next sections. This indirect approach will heavily rely on the role of a network of decentralized market participants to address the challenges of cryptocurrencies.

\section{Challenges to direct regulation}

Centralized direct regulation of cryptocurrencies may face the same challenges that the traditional command-and-control regulation does. The main challenge concerns the Hayekian knowledge problem. ${ }^{53}$ Traditional centralized regulation assumes that the government has the perfect knowledge to identify the causes of the problems and would have the complete knowledge and mastery of the regulatory instruments to design the best solutions to achieve its goals. And above all, it assumes that the government has the tools and resources to implement, and spot non-compliance, in particular, where the regulated industry is not sufficiently motivated to comply with such rules. ${ }^{54}$ From among all the

Working Paper in Economics No. 14-17 (2014). See also Jimmy Song, "Bits Denomination Bip," GitHub, https://github.com/bitcoin/bips/blob/master/bip-0176.mediawiki.

52 William J. Luther, "Cryptocurrencies, Network Effects, and Switching Costs," Contemporary Economic Policy 34, no. 3 (2016). (Luther believes that governments are capable of undermining bitcoin due to their ability to stifle network effects. He believes that in the absence of a major breakthroughs, it is unlikely that bitcoin would gain widespread adoption.) On the other side of the spectrum, some believe that profit seeking incentives of entrepreneurs can contribute to the widespread adoption of bitcoin. See Malavika Nair and Nicolás Cachanosky, "Bitcoin and Entrepreneurship: Breaking the Network Effect," The Review of Austrian Economics 30, no. 3 (2017).

${ }^{53}$ F. A. Hayek, "The Use of Knowledge in Society," The American Economic Review 35, no. 4 (1945).

${ }^{54}$ Julia Black, "Decentring Regulation: The Role of Regulation and Self Regulation in a "Post Regulatory" World," Current Legal Problems 54, no. 1 (2001): 106. 
challenges that centralized direct regulatory approaches face, three stand out in regulating cryptocurrencies: limitations on the competence of public authorities, identifying the regulated entities, and regulatory arbitrage.

\section{Limitations on competence}

One of the greatest challenges to regulating cryptocurrencies is that policymakers would lack competence over regulating cryptocurrencies. The basic principles of public and constitutional law imply that public entities, including regulators, have limited and enumerated powers and once their conducts or actions do not fall within one of those enumerated powers, they would be considered ultra vires and unconstitutional. In multi-layered constitutional arrangements such as that of the EU and the euro area, the principles of conferral, subsidiarity, and proportionality impose additional limitations on the powers of the EU institutions, agencies, and bodies. To ensure the compliance with this general principle, the regulators' acts and omissions intended to produce legal effects vis-à-vis third parties are often made subject to judicial review. ${ }^{55}$ For example, the supervisory competences of the ECB are limited to the prudential supervision of credit institutions within the Single Supervisory Mechanism (SSM) and the oversight of the payment system. Thus, the ECB can only intervene in the cryptocurrency markets if the cryptocurrencies threaten the stability of the payment or the banking systems. Therefore, the only option available for certain regulators, such as the ECB, is to indirectly supervise the cryptocurrency ecosystem through the banking system.

The question of regulatory competence and who should regulate cryptocurrencies depends on the approach to financial regulation as well. Although it is hard to shoehorn all financial regulatory systems in specific categories, at least four different approaches to the structure of financial regulation exist worldwide. These include the institutional, functional, integrated, and twin-peaks approaches. ${ }^{56}$ Despite their striking similarity to structural approaches, some financial regulatory and supervisory structures such as that of the US does not fit into any of the above categories. It is, however, a mix of functional and institutional approaches. ${ }^{57}$ The same applies to the EU which looks like a mix of institutional and twin-peaks approaches. Since cryptocurrencies cut across the traditional competences of various regulators and jurisdictions, they make the traditional classifications in the regulatory and supervisory

\footnotetext{
${ }^{55}$ See for example: Article 263 Treaty on the Functioning of the European Union (TFEU) and Article 35.1 of the ESCB/ECB Statute.

${ }^{56}$ Working Group on Financial Supervision The Group of Thirty, "The Structure of Financial Supervision: Approaches and Challenges in a Global Marketplace," (Washington, DC2008), 12-14. For a review of structures of financial regulation, see M. Taylor, "Institutional Structures of Regulation," in Handbook of Safeguarding Global Financial Stability: Political, Social, Cultural, and Economic Theories and Models, ed. Gerard Caprio Jr. (London: Elsevier Inc., 2013).; Heidi Mandanis Schooner and Michael W. Taylor, Regulation of Global Banking: Principles and Policies (Academic Press, 2010), 259-77.

${ }^{57}$ Working Group on Financial Supervision The Group of Thirty, "The Structure of Financial Supervision: Approaches and Challenges in a Global Marketplace," 12-14. A move from institutional and functional regime towards a modified Twin Peaks Approach is recommended for the US regulatory regime. See Treasury The Department of the, "Blueprint for a Modernized Financial Regulatory Structure," (2008).
} 
tasks virtually obsolete. ${ }^{58}$ In many jurisdictions, as traditional financial institutions, instruments, and activities are supervised by different financial regulators, cryptocurrencies - given their hybrid nature (i.e., currency, commodity, security) - are regulated by different financial markets authorities. It looks like each financial regulator depending on its existing mandate and fields of competences has engaged in regulation or supervision of the cryptocurrency ecosystem..$^{59}$

The origin of this controversy lies also in the nature of cryptocurrencies, their hybrid use-cases, and the fact that regulators are yet to come to a final conclusion on classifying cryptoassets. ${ }^{60}$ Although the debate about the legal nature of cryptocurrencies has significant legal implications, thus far, it has produced no conclusive result. Since there is no consensus about the nature of cryptocurrencies among regulators, ${ }^{61}$ there is no uniform approach to regulating them, ${ }^{62}$ nor is there any consensus about who should regulate them. The major cryptocurrencies have hybrid nature and cannot be fit into one of the traditional categories of money (currency), security or commodity. From a regulatory perspective, policymakers have taken different stances on the nature of cryptocurrencies. Tax authorities have designated cryptocurrencies as property. ${ }^{63}$ Commodity markets authorities have viewed them as a commodity. ${ }^{64}$ Securities regulators have seen some of them as security ${ }^{65}$ and regulators and supervisors in charge of money or financial crime have designated them as currency. Such a competence issue has been a constant concern for central banks and other regulatory agencies in dealing with cryptocurrencies and it constitutes a major roadblock to directly regulating cryptocurrencies particularly in the context of direct regulation.

Regulators need to exercise the utmost caution in the legal categorization of cryptocurrencies, as a legal categorization is not simply a description of reality. In effect, such categorizations prescribe the legal nature of objects. This means that putting one object into a specific legal category often triggers a whole host of legal consequences ${ }^{66}$ such as the determination of who should regulate that cryptocurrency.

\footnotetext{
${ }^{58}$ Bank for International Settlements, "Cryptocurrencies: Looking Beyond the Hype," in Annual Economic Report (Basel, SwitzerlandJune 2018), 108.

${ }^{59}$ For an overview of the regulation of cryptocurrencies around the world, see Global Legal Research Directorate Staff of the Library of Congress, "Regulation of Cryptocurrency in Selected Jurisdictions."

${ }^{60}$ See Financial Conduct Authority, "Guidance on Cryptoassets," Consultation Paper CP19/3 (January 2019): 8-9.

${ }^{61}$ See Commodity Futures Trading Commission, "In the Matter Of: Coinflip, Inc., D/B/a Derivabit, and Francisco Riordan, Respondents: Order Instituting Proceedings Pursuant to Sections 6(C) and 6(D) of the Commodity Exchange Act, Making Findings and Imposing Remedial Sanctions (Cftc Docket No. 15-29)," (September 17, 2015).; Securities and Exchange Commission, "Report of Investigation Pursuant to Section 21(a) of the Securities Exchange Act of 1934: The Dao," (Washington, DCJuly 25, 2017).

${ }^{62}$ Eswar Prasad, "Central Banking in a Digital Age: Stock-Taking and Preliminary Thoughts," 11-12.; Global Legal Research Directorate Staff of the Library of Congress, "Regulation of Cryptocurrency in Selected Jurisdictions."

${ }^{63}$ See Phoebus Athanassiou, "Impact of Digital Innovation on the Processing of Electronic Payments and Contracting: An Overview of Legal Risks," ECB Legal Working Paper Series No 16 (Octover 2017): 22-24.

${ }^{64}$ Commodity Futures Trading Commission, "In the Matter Of: Coinflip, Inc., D/B/a Derivabit, and Francisco Riordan, Respondents: Order Instituting Proceedings Pursuant to Sections 6(C) and 6(D) of the Commodity Exchange Act, Making Findings and Imposing Remedial Sanctions (Cftc Docket No. 15-29)."

${ }^{65}$ Securities and Exchange Commission, "Report of Investigation Pursuant to Section 21(a) of the Securities Exchange Act of 1934: The Dao."

${ }^{66}$ Rosa Maria Lastra and Jason Grant Allen, "Virtual Currencies in the Eurosystem: Challenges Ahead," (Brussels, Belgium: ECON Committee, European Parliament, 2018), 9.
} 
Therefore, legal categorization should only be sought, after the full appreciation of the object and its complexities.

Given the limited scope of the competences of the banking and payment regulators under the current regulatory framework, and as of the time of this writing, it seems that the regulation and supervision of cryptocurrencies by the banking regulators can only be in the form of indirect regulation. This means that it will mainly be conducted through their existing regulatory, supervisory and oversight tools that are conventionally exercised by the competent regulator over credit institutions and payment systems over which regulators have competence. In this view of regulation, although regulatory intervention may not touch the Bitcoin blockchain itself, it will apply at the use-case level, ${ }^{67}$ where the virtual comes into contact with the real.

This is particularly important in the context of evolving smart contracts on cryptocurrency schemes, where the external validation of the factual events (e.g., the actual transfer of the personal property) is necessarily conducted by trusted intermediaries (i.e., oracles). ${ }^{68}$ Not only can the reliance on the oracles reduce the level of trustlessness of transaction on the blockchain - long advocated by cryptocurrency enthusiasts - but also they become choke points for the purposes of regulation, where the law can target blockchain transactions. Regulating cryptoassets at the use-case level is likely to follow the functional definition of that currency as the regulation is based on the use-cases rather than other more abstract concepts.

\section{No relevant responsible target institution}

The direct, centralized and command-and-control based regulation of cryptocurrencies, to the extent possible, would run into the practical question of what or whom to regulate. The main problem with regulating cryptocurrencies is that decentralized permissionless blockchain-based cryptocurrencies are antithetical to the existing structure of financial regulation. Such cryptocurrencies do not fit into any existing frameworks. There is no easily identifiable legal entity or person towards which the regulation could be directed. Their domicile could be on or offshore or would be impossible to locate. ${ }^{69}$ Cryptocurrencies can also exist and function independently of the existing institutions and market infrastructures that makes taming them even more difficult.

There are a plethora of actors playing distinct roles in the cryptocurrency sphere, such as developers, issuers, miners, processing service providers, users, wallet providers, exchanges, and other trading platforms such as decentralized exchanges, merchant acceptance facilities, and various other actors. ${ }^{70}$

\footnotetext{
${ }^{67}$ Phoebus L. Athanassiou, Digital Innovation in Financial Services: Legal Challenges and Regulatory Policy Issues (Alphen aan den Rijn: Kluwer Law International B.V., 2018), 38.

${ }^{68}$ Primavera De Filippi and Samer Hassan, "Blockchain Technology as a Regulatory Technology: From Code Is Law to Law Is Code," First Monday 21, no. 12 (2016).

${ }^{69}$ Office of the New York State Attorney General, "Virtual Markets Integrity Initiative Report."

${ }^{70}$ For a detailed description, see European Central Bank, "Virtual Currency Schemes- a Further Analysis," 7-8.
} 
The issue becomes more complicated as some issuing organizations have neither managers nor real or corporate entity and place of domicile. Even in some cases, the identity of the developers is unknown.

All these features mean that cryptocurrencies can best be regulated indirectly focusing on the regulation of the known financial institutions and implementing the regulation through such institutions. ${ }^{71}$ Indirect regulation of cryptocurrencies would circumvent all those difficult questions and instead relegate them to a network of decentralized banks and payment institutions to address those problems. This regulatory approach has proven to be successful in the sanctions regimes, where the sanctioned country has the utmost incentive to circumvent the sanctions and undermine their effectiveness. In sanctions regimes, where the activity in question is out of reach of the regulator, the regulator targets the industry upon which it has jurisdiction, and sanctions the transactions between the regulated entities and those outside its regulatory reach (also known as secondary boycotts). ${ }^{72}$ Drawing such parallels, warnings issued by regulators such as the European Banking Authority (EBA) urging banks that engage or plan to engage in cryptocurrency business not to do so can be considered as regulatory interventions of this nature. ${ }^{73}$

To avoid the problems of direct regulation of the coders and the protocol, which could both be difficult in fact and on legal grounds, regulation of exchanges or identifiable wallet providers would be more suitable. ${ }^{74}$ The New York Bitlicense is a case in point where the businesses active in providing cryptocurrency services are the target of regulation. ${ }^{75}$ In this case, regulation targets the interface of cyberspace and the real world. This is in line with the old tradition in financial regulation where the regulation of financial markets and institutions has relied on gatekeepers. It seems that the regulation of cryptocurrencies is better to follow the same logic and focus on the institutions that are the point of converting cryptocurrencies to fiat currencies. In other words, the interface between cryptocurrencies and banks and payment institutions can be a point where the regulation can be targeted and deployed. ${ }^{76}$ Additional venues for indirect regulation would be for the regulator to focus on regulating liquidity providers in cryptocurrencies, and imposing stricter collateral eligibility requirements on the acceptance of cryptocurrencies as collateral by financial intermediaries, including banning such practices. ${ }^{77}$ However, even this type of regulation faces a few challenges, the most important of which was regulatory arbitrage, to which we return in the next section.

\footnotetext{
${ }^{71}$ Bank for International Settlements, "Cryptocurrencies: Looking Beyond the Hype," 107.

${ }^{72}$ Kern Alexander, Economic Sanctions: Law and Public Policy (New York: Palgrave Macmillan, 2009), 15.

${ }^{73}$ European Banking Authority, "Eba Opinion on 'Virtual Currencies'."

${ }^{74}$ Jason Albert, "What's Next for Blockchain: Technology, Economics and Regulation," Microsoft: EU Policy Blog (June 20, 2016).

75 Pete Rizzo, "New York Regulators Grant Second Bitlicense to Ripple," Coindesk (June 13, 2016).

${ }^{76}$ Phoebus L. Athanassiou, Digital Innovation in Financial Services: Legal Challenges and Regulatory Policy Issues, 88.

${ }^{77}$ Bank for International Settlements, "Cryptocurrencies: Looking Beyond the Hype," 108.
} 


\section{Regulatory arbitrage}

One important factor that plays a role in determining whom to regulate is the concerns about regulatory arbitrage. Regulatory arbitrage, broadly defined, refers to shifting activities from a heavily regulated financial sector to an unregulated or lightly regulated financial sector with the aim of maximizing profits by taking advantage of regulatory differentials. ${ }^{78}$ In doing so, it often "exploits the gap between the economic substance of a transaction and its legal or regulatory treatment." ${ }^{79}$ In the absence of barriers, a firm that is free to choose between two jurisdictions with differential regulatory costs will engage in business at lower regulatory costs. ${ }^{80}$

The relatively decentralized nature of cryptocurrencies and the young and nimble industries that are being evolved within this ecosystem create border problems ${ }^{81}$ and a wide scope for regulatory arbitrage across borders. ${ }^{82}$ In the cryptocurrency sphere, if a cryptocurrency is allowed only in one jurisdiction, it can spread across borders in the virtual environment and render the regulatory efforts of a single jurisdiction ineffective. This has already been the case in the regulator's cat and mouse game in the area of illegal download websites and decentralized protocols for P2P file sharing such as BitTorrent. ${ }^{83}$ Within such industries, due to the digital nature of the industry and its global reach, there is a possibility for regulatory arbitrage and a potential regulatory race to the bottom. Cryptocurrency regulation has not been an exception to this rule. For example, after the New York Bitlicense, there have been reports of businesses, including exchanges, that changed their domicile relatively quickly and with much ease unprecedented in the business history. In 2017, a year in which Bank of China took actions to regulate and ban ICOs, the cryptocurrencies ecosystem witnessed a shift in the global trading volume from Chinese Yuan (CNY) to Japanese Yen (JPY) and US dollar (USD).

The second problem is that due to the $\mathrm{P} 2 \mathrm{P}$ nature of these cryptocurrencies, banning or regulating them will presumably only push such currencies to the darker corners of the virtual world. Therefore, the problem of regulatory arbitrage itself again supports the case for an indirect regulatory approach, as it is far costlier for banks and other already regulated financial institutions to shift their business or relocate to less regulated jurisdictions. To be arbitrage-proof, regulation should, to the extent possible, link the mobile capital and elements of regulated firms to the immobile elements and impose regulation on immobile capital. In this way, the indirect regulation of cryptocurrencies targets the industries with limited capacity for mobility rather than the ones to whom the cost of relocation is small.

\footnotetext{
${ }^{78}$ Hossein Nabilou, "Regulatory Arbitrage and Hedge Fund Regulation: The Need for a Transnational Response," Fordham Journal of Corporate and Financial Law 22, no. 4 (2017).

${ }^{79}$ Victor Fleischer, "Regulatory Arbitrage," Texas Law Review 89, no. 2 (2010): 229.

${ }^{80}$ Andreas Engert, "Transnational Hedge Fund Regulation," European Business Organization Law Review 11, no. 03 (2010): 357.

${ }^{81}$ Charles A. E. Goodhart and Rosa M. Lastra, "Border Problems," Journal of International Economic Law 13, no. 3 (2010).; Charles Goodhart, "The Boundary Problem in Financial Regulation," National Institute Economic Review 206, no. 1 (2008).

${ }^{82}$ For the concept of regulatory arbitrage, see Hossein Nabilou, "Regulatory Arbitrage and Hedge Fund Regulation: The Need for a Transnational Response."

${ }^{83}$ Primavera De Filippi and Samer Hassan, "Blockchain Technology as a Regulatory Technology: From Code Is Law to Law Is Code."
} 
Targeting immobile or anchored elements of the industry within the direct regulatory approach is not unprecedented. For example, regulators in the EU decided to regulate hedge fund managers rather than hedge funds themselves, because, among others, it is more likely for the funds to be structured offshore and fall outside the jurisdiction of the regulator. In other words, the regulators decided to focus the regulation on the elements of the industry to whom the cost of relocation or regulatory arbitrage was higher. ${ }^{84}$ In this way, the regulation can prevent the relocation of players to loosely regulated financial markets. Again, putting criteria on (centralized) cryptocurrency investors or their sponsors can be considered as an example of such a strategy.

In addition, to effectively address regulatory arbitrage, special attention should be paid to incentive effects of regulation, i.e., a regulation that imposes additional costs on the regulated industry should offset those costs by offering the industry benefits of being subject to a specific regulatory regime. Ceteris paribus, the regulatory system in which the marginal benefits of regulation equal its marginal costs can become arbitrage-proof. Therefore, the design of a regulatory regime for cryptoassets should result in an equilibrium from which cryptocurrency businesses have no incentive to deviate without making themselves worse off.

Not to mention, there is no panacea for addressing regulatory arbitrage and all the attempts for doing so are imperfect and only can mitigate the problem imperfectly. So are the indirect regulation-based proposals. Eventually, a degree of global coordination might be necessary to effectively mitigate the risks of regulatory arbitrage in this context. ${ }^{85}$ However, indirect decentralized regulatory approach is susceptible to regulatory arbitrage to a lesser degree. ${ }^{86}$ Therefore, to face the challenges stemming from decentralized systems, it seems there is a need for certain levels of decentralization in the structure of regulation itself. For this restructuring to take place, there is no need for reinventing the wheel. Instead, regulation can be decentralized in a very traditional meaning of the term to deal with the problems arising from cryptocurrencies, irrespective of the degree of decentralization in the cryptocurrency ecosystem. Indirect regulation through credit institutions and payment systems and reliance on soft law in crafting international financial regulatory standards would be a promising way forward in avoiding potential problems stemming from regulatory arbitrage.

\section{Decentralized indirect regulation of cryptocurrencies}

The more interesting feature of indirect regulation that makes it particularly suitable for the regulation of cryptocurrencies is its relatively decentralized nature. ${ }^{87}$ In this respect, crafting appropriate indirect

\footnotetext{
${ }^{84}$ See Hossein Nabilou, "Regulatory Arbitrage and Hedge Fund Regulation: The Need for a Transnational Response."

${ }^{85}$ Bank for International Settlements, "Cryptocurrencies: Looking Beyond the Hype."

${ }^{86}$ Hossein Nabilou, "Regulatory Arbitrage and Hedge Fund Regulation: The Need for a Transnational Response."

${ }^{87}$ For the concept of decentred regulation, see Julia Black, "Decentring Regulation: The Role of Regulation and Self Regulation in a "Post Regulatory" World.". The decentralized regulation aspect is in line with a technology-enabled 'polycentric co-regulatory' approach that has recently gained traction. See Michèle Finck, Blockchain Regulation and
} 
regulatory mechanisms for cryptocurrencies requires identifying the financial institutions that have the most continuous and day-to-day relationships with them. Identifying these institutions means identifying those equipped with sufficient knowledge and understanding of the industry and their activities in financial markets. ${ }^{88}$ These are the institutions that can potentially be used as 'surrogate regulators' delegated with regulatory functions from government agencies. Furthermore, since indirect regulation of cryptocurrencies will be implemented by different multiple banks and payment institutions, it provides for the possibility of decentralized implementation and enforcement of rules which are initially applied to the banking and payment sector.

The indirect regulation of cryptocurrencies will more closely resemble standards as opposed to rules. ${ }^{89}$ This approach can transform rules-based regulation into principles-based regulation when credit and payment institutions - rather than the regulator itself - implement it. This is to say that precise rules made by the regulator and applied to credit and payment institutions will be transformed into standards in at least three aspects. First, the application, implementation, and enforcement of rules will be more decentralized and conducted by surrogate regulators. Second, rules will be applied with more flexibility, allowing for more variations in details and implementation. Third, rules will be applied with more discretion, making them resemble standards. In other words, indirect regulation is a means that can turn rules into standards when applied to the primary target of regulation..$^{90}$

For example, under the indirect regulation approach, central banks and other banking and payment regulators would regulate the entities or intermediaries enabling the interface and interaction between cryptocurrencies and fiat currency in cryptocurrencies schemes with the bidirectional flow. ${ }^{91}$ For certain transactions, especially in the realm of payments, indirect regulation, which targets intermediaries, is only possible in off-chain transactions where intermediaries are involved in the transaction. In contrast, due to the absence of intermediaries in most on-chain transactions, indirect regulation cannot target them. The intermediaries in off-chain transactions may include cryptocurrency banks and lenders, exchanges and wallet providers, custodians, and merchant acceptance facilities. For instance, for user protection purposes, account segregation requirements (separation of clients' accounts) can be imposed on identifiable wallet providers, exchanges and custodians. As fractional reserve banking on bitcoin -

Governance in Europe (Cambridge: Cambridge University Press, 2019), 172-78. For the concept of coregulation, see: European Commission, International Agreement on Better Law-Making, 2003 OJ C 321/01, para 18.

${ }^{88}$ In this sense, indirect regulation becomes very similar to the regulation by standards, because it relies on the decentralized knowledge. For more information about how standards involve utilizing such knowledge. See Hans-Bernd Schaefer, "Legal Rule and Standards," in The Encyclopedia of Public Choice, Volume I, ed. Charles K. Rowley and Friedrich Schneider (New York: Kluwer Academic Publishers, 2004).

${ }^{89}$ For the distinction between rules vs. standards, see Isaac Ehrlich and Richard A. Posner, "An Economic Analysis of Legal Rulemaking," The Journal of Legal Studies 3, no. 1 (1974): 258, 61.; Louis Kaplow, "Rules Versus Standards: An Economic Analysis," Duke Law Journal 42, no. 3 (1992).; Hans-Bernd Schaefer, "Legal Rule and Standards."; Cass R. Sunstein, "Problems with Rules," California Law Review 83, no. 4 (1995): 1021-23.; Pierre Schlag, "Rules and Standards," UCLA Law Review 33 (1985): 424-25.

${ }^{90}$ See Hossein Nabilou and Alessio M. Pacces, "The Hedge Fund Regulation Dilemma: Direct Vs. Indirect Regulation."

${ }^{91}$ European Central Bank, "Virtual Currency Schemes," 13-14. 
despite its specific problems - is likely to take off, ${ }^{92}$ financial institutions engaged in the fractional reserve banking on bitcoin may be treated as ordinary lenders and borrowers, only with a higher risk profile. Needless to say, higher prudential requirements would apply to such intermediaries to offset the higher risks of cryptocurrencies. For example, in implementing such a strategy, ring-fencing the traditional banking and payment systems can be considered as a policy option.

As another example, a regulatory strategy aimed at reducing leverage in the cryptocurrencies ecosystem can do so by imposing leverage restrictions (including qualitative and quantitative collateral rules) on credit or payment institutions that engage in lending (both in fiat and cryptocurrency) to the market participants in the cryptocurrencies ecosystem. A cap on the bank's leverage can be translated into effective but variable caps on cryptocurrency firms' leverage to the extent they rely on credit institutions for borrowing. In this case, it is the credit institution that will allocate the credit to cryptocurrency firms. By doing so, instead of directly putting a limit on the leverage on the cryptocurrency industry, the regulator effectively delegates the allocation of credit to the banks that possess a superior knowledge of lending in general and the industry in particular. Although such a leverage requirement imposed originally by the regulator would operate as a rigid and non-discretionary rule for banks, it will have the flexibility of standards for cryptocurrency firms. This is because banks can customize the level of leverage and make loans to every cryptocurrency customer according to its financial standing and the bank's own safety and soundness standards. In turn, cryptocurrency firms that value leverage the most would apply for more loans, and because banks are more efficient in monitoring borrowers, they will have more flexibility in allocating leverage or credit on behalf of regulators. Because cryptocurrency firms themselves, in turn, can lend to and borrow from each other, such a regulatory cap on credit institutions' leverage can, in essence, take the form of 'leverage cap and trade'. In the end, such discretion would provide flexibility in the allocation of loans or leverage to cryptocurrency firms and result in an effective cap and more efficient allocation of credit in the ecosystem. ${ }^{93}$

In the following sections, the paper investigates the potential venues for indirect regulation. It first highlights the role of more recent technical developments and how they open up new opportunities for the indirect regulation of cryptocurrencies. Thereafter, it highlights the role of the banking and payment institutions in implementing such a regulatory strategy.

\section{Technical developments and new venues for decentralized regulation}

From its earliest days of bitcoin, scaling issues have been a constant concern for all the participants in the Bitcoin network, which led to significant developments and dividing controversies in the bitcoin

\footnotetext{
${ }^{92}$ Some commentators believe that the introduction of Bakkt by the Intercontinental Exchange (ICE), the parent company of the New York Stock Exchange (NYSE), would lead to fractional reserve banking on bitcoin. It seems that the USDT (Tether) has already engaged in the some kind of fractional reserve banking on its stablecoin. And there are firms that pay interest on the bitcoin balances (fractional reserve bitcoin).

${ }^{93}$ Hossein Nabilou and Alessio M. Pacces, "The Hedge Fund Regulation Dilemma: Direct Vs. Indirect Regulation."
} 
community. Two main camps emerged; one supporting vertical scaling solutions or the so-called second-layer solutions, ${ }^{94}$ the other supporting horizontal scaling solutions or increasing the current onemegabyte block size. ${ }^{95}$ The ensuing civil war among the bitcoin community resulted in the failed SegWit2X, and a hard fork leading to the creation of bitcoin cash $(\mathrm{BCH})$ and subsequent user activated soft fork (UASF) and the activation of SegWit in the legacy chain. ${ }^{96}$ Through time, it seems that within the bitcoin community vertical scaling solutions or the so-called second-layer solutions to address Bitcoin's scalability problems is gaining traction. ${ }^{97}$ From among these new solutions, proposals for addressing scaling problems with the Bitcoin protocol such as the Lightning Network ${ }^{98}$ stand out.

The second-layer solutions have already been in the making from the early days of bitcoin. Exchanges, bitcoin custody solution providers, and bitcoin debit card providers, which allow the internal or external transfers of bitcoin from a wallet to another within or across companies, can be considered as part of the second-layer scaling solutions for bitcoin. Furthermore, fractional reserve banking on bitcoin can act as a second-layer solution to address certain existing scaling problems. Banking on bitcoin is not a new idea and has been proposed even in the early days of bitcoin by some very early bitcoin users and developers as a scaling solution. ${ }^{99}$ In this view, banks would function as an additional layer on Bitcoin and the Bitcoin protocol itself would serve as the base or settlement layer for the net settlement of the financial obligations arising from the banking industry developed on top of Bitcoin. Upon realization of such developments, banks and payment service providers can directly or indirectly engage in the vertical layers of bitcoin by evolving into wallet providers, custodians, and nodes that support payment channels such as those of the Lightning Network.

The second layer payment channels within the Lightning Network pose different challenges, such as liquidity risks that would warrant special scrutiny if banking entities would run full nodes on the Lightning Network. In addition, the transactions on the Lightning Network provide for higher levels of privacy than on-chain transactions do. Developments of this kind may warrant regulatory intervention. However, this time, due to lower levels of decentralization, the task of the regulator could be much easier and focused on the identifiable node operators on the network.

\footnotetext{
${ }^{94}$ See: Andreas M. Antonopoulos, Mastering Bitcoin: Programming the Open Blockchian (Sebastopol, CA: O’Reilly Media, Inc.,, 2017), 300-21.

${ }^{95}$ See Joseph Poon and Thaddeus Dryja, "The Bitcoin Lightning Network: Scalable Off-Chain Instant Payments."; Aaron van Wirdum, "The History of Lightning: From Brainstorm to Beta," Bitcoin Magazine (4 April 2018).; Tom Elvis Jedusor, "Mimblewimble," (19 July 2016).; Aaron van Wirdum, "Mimblewimble: How a Stripped-Down Version of Bitcoin Could Improve Privacy, Fungibility and Scalability All at Once," Bitcoin Magazine (12 August 2016).

${ }^{96}$ Laura Shin, "Will This Battle for the Soul of Bitcoin Destroy It?," ForbesOct. 23, 2017.. Similar controversies happened on the Ethereum' blockchain due to the loss of funds associated with DAO project, resulting in a chain split and the creation of Ethereum and Ethereum Classic.

${ }^{97}$ See Andreas M. Antonopoulos, Mastering Bitcoin: Programming the Open Blockchian, 300-21.

98 Joseph Poon and Thaddeus Dryja, "The Bitcoin Lightning Network: Scalable Off-Chain Instant Payments."; Aaron van Wirdum, "The History of Lightning: From Brainstorm to Beta."

${ }^{99}$ Hal Finney, "Re: Bitcoin Bank," (December 30, 2010).
} 


\section{Regulating cryptocurrency through the banking system}

Regulating cryptocurrencies through banks may have various underlying rationales. It may be due to the customer or investor protection concerns, due to the financial integrity concerns, or due to the potential systemic risks concerns. Banks and cryptocurrencies have an uneasy relationship. On the one hand, there is a likelihood that the cryptocurrency business would grab part of the business of banking. On the other hand, to avoid such an outcome, banks may take an active role and engage in cryptocurrencies. The first line of business of traditional banking, which is more likely to fall victim to cryptocurrencies, is the payment service provision by banks, especially correspondent-banking model of international fund transfers. However, banks might take a proactive approach and coopt cryptocurrency business even in the provision of payment services. Bank involvement in cryptocurrencies could take various forms. The first role banks can play in cryptocurrency ecosystems is to function as an onramp for new entrants and investments in cryptocurrencies by providing banking services, in particular deposit or transaction accounts, to cryptocurrency business. In addition, banks may engage in offering cryptocurrency accounts or wallets or establish proprietary trading desks in cryptocurrencies or offer cryptocurrency Exchange Traded Fund (ETFs) or derivative products. ${ }^{100}$ Such activities can raise a few important regulatory questions. For example, should the regulator ban trading in cryptocurrencies for the banks or should it impose structural regulation, such as ring-fencing or subsidiarization? Given the liquidity risks in the cryptocurrency business and its derivatives, regulators would consider ring-fencing between proprietary trading in cryptocurrencies and other activities of banks to avoid cross-subsidization of cryptocurrency proprietary trading by the governments' implicit and explicit subsidies to banks. ${ }^{101}$

Cryptocurrencies are likely to affect the payment function of banks, however, the impact on deposittaking and lending would be minimal. Therefore, it is less likely that the maturity and liquidity transformation by banks would be disrupted by the cryptocurrency businesses. Although at the time of this writing, borrowing and lending cryptocurrencies are not taking place in the banking sector, ${ }^{102}$ this may be subject to change in the future. Therefore, further regulatory issues would involve the regulatory treatment of the engagement of banks in borrowing and lending in cryptocurrencies and the use of cryptocurrencies as collateral. For example, what safeguards should be in place to alleviate the risks of maturity and liquidity transformation in the absence of a lender of last resort (LOLR) with access to unlimited sources of liquidity? ${ }^{103}$ Additional prudential questions would be whether cryptocurrencies should be allowed to be used as collateral in the banking industry for secured financing. And if so, what quantitative and qualitative standards to be used for determination of haircuts in accepting

\footnotetext{
${ }^{100}$ Nathaniel Popper, "Goldman Sachs to Open a Bitcoin Trading Operation," The New York Times May 2, 2018.

${ }^{101}$ See Hossein Nabilou, "Bank Proprietary Trading and Investment in Private Funds: Is the Volcker Rule a Panacea or yet Another Maginot Line?."

102 Though some lending platforms engage in cryptocurrency lending and some exchanges do margin lending at the moment.

${ }^{103}$ Examples would be imposing prudential rules on lending, such as large exposure limits, interbank exposure, etc.
} 
cryptocurrencies as collateral? How should the margins (initial and variation margins) be set on cryptocurrencies and their derivatives? Should there be special regulatory capital, leverage, and liquidity requirements for the exposure to cryptocurrencies? All these questions would open up venues for the regulation of cryptocurrencies indirectly by banking regulators.

A major problem in cryptocurrency markets remains to be liquidity risks for the users. In addition to the technical limitations on the monetary policy embedded in the protocol, cryptocurrencies have only exchange value but little use value (intrinsic value). This means that in distressed times it is likely that liquidity issues would lead to large scale volatility. If banks directly or indirectly involve in liquidity provision in the cryptocurrency markets or are exposed to such liquidity risks, prudential measures should be set in place to protect the banking system. For example, if banks engage in fractional reserve banking on bitcoin, they would directly or indirectly be exposed to liquidity problems of cryptocurrencies. In this case, central banks as LOLRs would consider either cutting access to the LOLR service or imposing restrictions (or stricter liquidity standards) on the banks that engage in such activities. In the eurozone, the ECB is the de facto LOLR service provider (equivalent to Fed's discount window) through the marginal lending facility. ${ }^{104}$ The reason that the ECB can be the LOLR is that it has access to unlimited sources of liquidity. The predetermined supply schedule and fixed money supply model of cryptocurrencies such as bitcoin remove the possibility of an ultimate liquidity provider or a LOLR. ${ }^{105}$

Since the likelihood of the banking system engaging in cryptocurrencies would be the major source of systemic risk concerns in the future, banking supervisors can indirectly reduce the likelihood of risk of cryptocurrencies channeling through banking and payment systems by focusing on the prudential supervision of credit and payment institutions, rather than engaging in the regulation of cryptocurrencies themselves. For example, prohibiting banks from opening a bank account for cryptocurrency exchanges can stifle the growth of cryptocurrencies by creating roadblocks on the onramps to the cryptocurrency ecosystem. This would effectively function as the size limit or leverage limit on the cryptocurrency ecosystem as they would be deprived of the main sources of credit in the economy. ${ }^{106}$

\footnotetext{
104 This is made redundant by the introduction of fixed rate full allotment policy (FRFA). See Carlos Garcia-de-Andoain et al., "Lending-of-Last-Resort Is as Lending-of-Last-Resort Does: Central Bank Liquidity Provision and Interbank Market Functioning in the Euro Area," ECB Working Paper Series No 1886 (2016): 10.

${ }^{105}$ Although some proposals for stablecoins, such as Basis, allow such algorithmic central banking that provides for price stability using flexibility in money supply, it is unlikely that those stablecoin experiments would succeed in the presence of a credible CeBM. See: https://www.basis.io/. For a critique of this project, see Jemima Kelly, "The John Taylor-Backed "Stablecoin" That's Backed by, Um, Stability," Financial Times June 25, 2018. This project was shut down in December 2018, perhaps due to its shaky economic foundations. See Fabian Schär and Aleksander Berentsen, "Stablecoins: The Quest for a Low-Volatility Cryptocurrency," in The Economics of Fintech and Digital Currencies, ed. Antonio Fatás (London: CEPR Presss, 2019).

${ }^{106}$ For example, if the KYC/AML/CFT regulations would prevent banks from engaging in cryptocurrency businesses, cryptocurrency exchanges would have difficulty in opening accounts in the banks and hence would be deprived of one of their main gates through which the retail client's money would flow into the cryptocurrencies.
} 
Moreover, as mentioned earlier, technological developments open up further opportunities for indirect regulation as the banking system may perform different roles in, for example, the second-layer solutions of the Bitcoin network. As the scaling solutions for cryptocurrencies are being developed, it seems that the majority of the activities within the cryptocurrency ecosystem would migrate to second layers, and the protocol level would only be used for secure (deferred) net settlements (DNS). As participants in the second layers are likely to be banks, payment institutions and other financial institutions, the powers of the banking and payment supervisors in the supervision of credit institutions and payments system will be of utmost importance. Such developments not only necessitate new sets of regulation that should be imposed on banks but also turn the bank into suitable surrogate regulators through which the regulator can pursue its policy objectives by targeting the gatekeeping functions of a bank. In this sense, a majority of banking regulations would have their indirect impact on the cryptocurrency ecosystem.

\section{Regulating cryptocurrencies through payment institutions}

Recent developments in the EU and elsewhere in the world show that the payment institutions are increasingly involved in the cryptocurrency business. ${ }^{107}$ Risks in the payment systems mainly include credit risk, liquidity risk, operational risk, legal risk, and systemic risk. ${ }^{108}$ To address such risks, payment systems in Europe as part of the FMIs rests on an edifice of robust institutional and legal infrastructure. In addition to the laws and regulations regarding the retail payment systems, there is an established legal framework including ECB guidelines and decisions for the wholesale payment systems to address operational, liquidity and counterparty risks as well as settlement finality risks of such systems. ${ }^{109}$ However, the above mentioned legal framework does not apply to the payments made using cryptocurrencies. ${ }^{110}$ Therefore, such payments in their current form cannot be considered as a safe method of payment, not only due to the volatility of the settlement asset and probabilistic finality of the settlements but also because, unlike central bank money (CeBM), general acceptability of cryptocurrencies cannot be guaranteed. ${ }^{111}$

Since the ultimate goal of many cryptocurrency schemes is to become a payment system ${ }^{112}$ either in parallel with the existing payment infrastructure or replacing them, and as some cryptocurrencies share

\footnotetext{
${ }^{107}$ Hossein Nabilou, "The Dark Side of Licensing Cryptocurrency Exchanges as Payment Institutions," SSRN Working Paper Series (2019).

108 European Central Bank, The Payment System: Payments, Securities and Derivatives, and the Role of the Eurosystem (Frankfurt am Main: European Central Bank, 2010), 115-30. For an overview of legal risks in the use of cryptocurrencies as payment media, see Phoebus Athanassiou, "Impact of Digital Innovation on the Processing of Electronic Payments and Contracting: An Overview of Legal Risks," ECB Legal Working Paper Series No 16 (October 2017): 16-18.

${ }^{109}$ In particular, this framework is of utmost importance in systemically important payment systems (SIPS) and in wholesale payment systems such as Target2 (Trans-European Automated Real-time Gross Settlement Express Transfer System), T2S (Target2-Securities), CLS (Continuous Linked Settlement), and provides legal certainty on collateral and finality of settlements.

${ }^{110}$ Except those rules applicable to financial fraud or financial crime.

${ }^{111}$ European Central Bank, "Virtual Currency Schemes," 40.

112 This is also acknowledged in the ECJ decision. “... the 'bitcoin' virtual currency has no other purpose than to be a means of payment”. See Skatteverket v David Hedqvist, Court of Justice of the European Union, Case C-264/14, 6 (July 2015 ). § 24.
} 
many features of media of payments, they may fall within the regulatory ambit of the existing payment services regulation. ${ }^{113}$ In this respect, the rationale for regulation would be mainly about the integrity of the payment systems and safety of the transactions. However, the ultimate impact of cryptocurrencies on the payment system, it seems that this impact can both be positive and negative. On the one hand, if cryptocurrencies become a major method of payments in the future and sideline the official payment systems, their potential technological vulnerabilities could jeopardize the stability of the payment systems. An additional concern is that the fragmentation and lack of regulation and oversight over the decentralized payment system can lead to concentration of counterparty risks in payment hubs (e.g., on the Lightning Network) which would result in the fragility of the cryptocurrency payment system. ${ }^{114}$ Furthermore, where cryptocurrencies are used as a settlement asset, the finality and irrevocability of payments cannot be legally guaranteed. This problem also exists at a technological level. ${ }^{115}$ On the other hand, a decentralized payment system can be more resilient in the face of natural disasters and other calamities. In addition, the coexistence of payment systems can increase payment system stability by creating an additional level of redundancy ${ }^{116}$ where in case of a failure of one system, there would be a second option. In other words, the proliferation of different methods of electronic payments and the addition of multiple levels of redundancies to the existing structures could result in a more robust payment system leading to enhanced financial stability. ${ }^{117}$

Despite their benefits, cryptocurrency payments may be used for illicit purposes, the transactions could be subject to idiosyncratic technical risks and the users' funds may be lost in the event of the failure of the middlemen facilitating the cryptocurrency transactions. For example, bitcoin payments are mainly gross and (near) real time. ${ }^{118}$ Hence, they may be subject to substantial liquidity risks. Concerns about liquidity risks have been raised about bitcoin in the sense that it is impossible to have full decentralization, fixed money supply, and sufficient liquidity simultaneously. ${ }^{119}$ Although cryptocurrencies would be prone to liquidity risks, as of yet, there has been no documented risks to the conventional payment systems posed by illiquidity in cryptocurrencies. However, the involvement of banks in cryptocurrency payment systems might result in risk spillovers from the latter to the former.

\footnotetext{
${ }^{113}$ European Central Bank, "Virtual Currency Schemes- a Further Analysis," 27-28. See also Article 22 of the ESCB/ECB Statute.

${ }^{114}$ Eswar Prasad, "Central Banking in a Digital Age: Stock-Taking and Preliminary Thoughts," 14.

${ }^{115}$ Bank for International Settlements, "Cryptocurrencies: Looking Beyond the Hype," 102.

${ }^{116}$ Eswar Prasad, "Central Banking in a Digital Age: Stock-Taking and Preliminary Thoughts," 14.

117 Ibid.

118 Although there is no counterparty default risk in bitcoin transactions, using bitcoin exposes the users to operational or technical risks stemming from the settlement finality risks. As will be explained in section 4 of this paper, transactions in bitcoin often are batched by the miners and appended to the latest blockchain which on average takes ten minutes. During this time and the time that is required for the transaction to be deemed final (customarily six confirmations taking approximately sixty minutes), the users are exposed to the technical or operational risks. Therefore, bitcoin transactions are not real-time. Though they cannot be viewed as the equivalent of Deferred Net Settlement (DNS) Systems as they do not offer the advantages of that system in terms of economizing on liquidity and do not have counterparty default risks between the execution and settlement endemic to the DNS systems. For the lack of a better term, we use near real-time settlement.

${ }^{119}$ Frances Coppola, "Lightning Network May Not Solve Bitcoin's Scaling 'Trilemma'," CoindeskJanuary 20, 2018.
} 
From among the efforts aimed at bringing cryptocurrencies within the regulatory net, licensing requirement has been considered as the first natural step. However, it was not evident which type of license to be issued for engaging in cryptocurrency activities. In certain jurisdictions, such as in New York, where Bitlicense is issued, regulators decided to create a specific license for such activities. ${ }^{120}$ Other jurisdictions opted for granting payment institution license to cryptocurrency exchanges. For example, in Luxembourg, Bitstamp Europe S.A. and bitFlyer Europe S.A., which provide the possibility of cross-border transfers of cryptocurrencies across wallets and across exchanges, are licensed as payment institutions. ${ }^{121}$ Licensing cryptocurrency exchanges as payment institutions is a regulatory strategy that is a first step in extending the existing regulations to the participants of cryptocurrency ecosystems. However, cryptocurrency payments are subject to idiosyncratic risks that cannot be fully addressed even assuming the full applicability of the payment services laws to the cryptocurrency exchanges. Two prominent examples of such risks are the risks associated with the illiquidity and volatility of the settlement asset in cryptocurrency payments, and the risks arising from the probabilistic finality of the settlements in blockchains relying on probabilistic finality. ${ }^{122}$

Therefore, it seems that licensing cryptocurrency exchanges as a payment institution would do more harm than good in the long run. The alternative indirect regulation, i.e., directing the regulations towards the relationship of payment institutions and cryptocurrencies, would be a better strategy. Although under the current legal framework, direct intervention in the cryptocurrency markets may need extending the legal mandate of the existing regulators, the need for such an extension does not seem necessary at the time of this writing. The main reason being that the indirect tools at the disposal of the regulators are likely to address the potential risks stemming from the cryptocurrency ecosystem.

Within such an indirect regulatory framework, a major venue through which cryptocurrencies can be regulated due to their interaction with the payment systems is through the regulators' power of prudential supervision over credit institutions as banks engage in the provision of payment services. There are several scenarios in which banks might engage in payment systems using bitcoin or other cryptocurrencies. For example, as the second-layer payment solutions are being developed for bitcoin, banks might engage in the second-layer payment channels by running full nodes on the Lightning Network, ${ }^{123}$ essentially providing liquidity in bitcoin. Whether running such nodes and engaging in transactions in the second-layer payment channels mean that the bank engages in the provision of retail payment services and the application of payment laws should be triggered and whether the payments relayed through the blockchain qualify as wholesale payments system remain open questions.

\footnotetext{
${ }^{120}$ New York Department of Financial Services, New York Codes, Rules and Regulations; Title 23, Department of Financial Services, Chapter I. Regulations of the Superintendent of Financial Services, Part 200, Virtual Currencies

${ }^{121}$ See Commission de Surveillance du Secteur Financier (CSSF), "Newsletter No. 157," news release, February 2014, http://www.cssf.lu/fileadmin/files/Publications/Newsletter/Newsletter_2014/newsletter157eng.pdf.; See also Jean-Louis Schiltz and Nadia Manzari, "The Virtual Currency Regulation Review: Luxembourg," The Law Reviews (2018).

${ }^{122}$ Hossein Nabilou, "The Dark Side of Licensing Cryptocurrency Exchanges as Payment Institutions."

123 Joseph Poon and Thaddeus Dryja, "The Bitcoin Lightning Network: Scalable Off-Chain Instant Payments."; Aaron van Wirdum, "The History of Lightning: From Brainstorm to Beta."
} 
Nevertheless, such developments open up new opportunities for indirect regulation of cryptocurrency payments through the banking system.

\section{Summary and conclusion}

This paper has been an endeavor in pursuit of the most efficient and effective regulatory strategies for regulating decentralized cryptocurrencies such as bitcoin. By taking the policy debate about regulating bitcoin a step further from whether to how to regulate bitcoin, the paper identifies two overarching regulatory strategies for regulating decentralized cryptocurrencies: centralized direct regulation and decentralized indirect regulation. It shows that centralized, direct, command-and-control regulation of cryptocurrencies face serious insurmountable challenges in regulating cryptocurrencies. They include limitations of competence on regulators, the fact that in certain cryptocurrencies there is no relevant responsible target institution towards which the edicts of regulation would be directed, and the problem of regulatory arbitrage that may thwart regulatory initiatives due to the features that are unique to the cryptocurrency industry.

After highlighting the limitations of the centralized, direct, command-and-control regulation of cryptocurrencies, it argues that the focus of regulating decentralized cryptocurrencies should be shifted from the protocol layers towards the upper layers (i.e., application layers) upon which businesses are being developed. It is highly likely that the interface between the virtual and the real would be evolved around these layers where businesses would start building applications for micropayments and other payment purposes. As it is likely that certain levels of centralization in the upper layers would emerge, opportunities for regulators would come forth to direct the edicts and interdictions of regulations toward those entities, which are involved in the application layers of decentralized cryptocurrencies, through the banking and payment systems that can play the role of surrogate regulators. By the choice of standards over rules and granting discretion to surrogate regulators in the application of those standards to the cryptocurrency ecosystem, this indirect regulatory approach can achieve a level of decentralization that is likely to increase effectiveness and efficiency of regulation. This semidecentralized regulatory model, which is built on the concept of market-based, bottom-up and indirect regulation, ${ }^{124}$ is one of the most promising methods of regulation that could work with minimum regulatory costs and could avoid the inertia that hinders creating a new institutional framework for regulating cryptocurrencies.

Given the innovative and idiosyncratic nature of bitcoin as being the first digital, divisible, denationalized, peer-to-peer and globally transferable store of value, and the potential layers of

\footnotetext{
${ }^{124}$ See Colin Scott, "Accountability in the Regulatory State," Journal of Law and Society 27, no. 1 (2000).; Colin Scott, "Regulation in the Age of Governance: The Rise of the Post-Regulatory State," in The Politics of Regulation: Institutions and Regulatory Reforms for the Age of Governance, ed. Jacint Jordana and David Levi-Faur (Northampton, Massachusetts: Edward Elgar Publishing, Inc., 2004).
} 
innovative ideas that can be built upon it, an aggressive command-and-control approach to its regulation would stifle the potential future innovations that would be built upon Bitcoin's protocol layer and that are hard to conceive of at the time of writing. Viewing Bitcoin as an evolving work-in-progress warrants a nuanced light-touch regulatory approach which is data dependent, defers to the virtues of experimentation, spontaneous discovery process ${ }^{125}$ and evolutionary dynamics in the financial system. ${ }^{126}$ In this perspective, one of the main advantages of decentralized model of regulation is that it is best suited to address the Hayekian knowledge problem as the regulation is more likely to rely on the existing market players, who have constant and day-to-day interactions with the industry, and are best suited to be knowledgeable about the constantly evolving cryptocurrency ecosystem. If adequate measures would be put in place to prevent regulatory capture, such a constant exposure would ensure that the rules and standards ultimately applicable to cryptocurrencies could be evolved in tandem with the evolution of the cryptocurrency ecosystem.

\footnotetext{
125 Israel M. Kirzner, "The Perils of Regulation: A Market-Process Approach , 119-49.," in Discovery and the Capitalist Process, ed. Israel M. Kirzner (Chicago: University of Chicago Press, 1985).

${ }^{126}$ Simon A. Levin and Andrew W. Lo, "Opinion: A New Approach to Financial Regulation," Proceedings of the National Academy of Sciences 112, no. 41 (2015).; Andrew W. Lo, Adaptive Markets: Financial Evolution at the Speed of Thought (Princeton: Princeton University Press, 2017).
} 


\section{Bibliography}

Albert, Jason. "What's Next for Blockchain: Technology, Economics and Regulation." Microsoft: EU Policy Blog (June 20, 2016).

Alexander, Kern. Economic Sanctions: Law and Public Policy. New York: Palgrave Macmillan, 2009.

Andolfatto, David. "Fedcoin: On the Desirability of a Government Cryptocurrency." MacroMania 2018 (February 03, 2015).

Anonymous (32E3690D50B3B477DF7841212D4BB938DC9CDB50307618328E7F8B53F37CC1E2). "Quantifying the Effect of Tether." January 24, 2018.

Antonopoulos, Andreas M. Mastering Bitcoin: Programming the Open Blockchian. Sebastopol, CA: O’Reilly Media, Inc.,, 2017.

Athanassiou, Phoebus. Hedge Fund Regulation in the European Union: Current Trends and Future Prospects. Alphen aan den Rijn (The Netherlands): Kluwer Law International, 2009.

. "Impact of Digital Innovation on the Processing of Electronic Payments and Contracting: An Overview of Legal Risks." ECB Legal Working Paper Series No 16 (October 2017).

. "Impact of Digital Innovation on the Processing of Electronic Payments and Contracting: An Overview of Legal Risks." ECB Legal Working Paper Series No 16 (Octover 2017).

Athanassiou, Phoebus L. Digital Innovation in Financial Services: Legal Challenges and Regulatory Policy Issues. Alphen aan den Rijn: Kluwer Law International B.V., 2018.

Auer, Raphael. "Beyond the Doomsday Economics of "Proof-of-Work" in Cryptocurrencies." BIS Working Papers No 765 (2019).

Austin, John. The Province of Jurisprudence Determined. New York: Cambridge University Press, 2001.

Bal, Aleksandra. "How to Tax Bitcoin?". Chap. 14 In Handbook of Digital Currency: Bitcoin, Innovation, Financial Instruments, and Big Data, edited by David Lee Kuo Chuen, 267-82. San Diego, CA: Academic Press, 2015.

Bank for International Settlements. "Cryptocurrencies: Looking Beyond the Hype." In Annual Economic Report. Basel, 2018.

Barontini, Christian, and Henry Holden. "Proceeding with Caution - a Survey of Central Bank Digital Currency." BIS Papers No 101 (January 2019).

Barrdear, John, and Michael Kumhof. "The Macroeconomics of Central Bank Issued Digital Currencies." Bank of England Staff Working Paper No. 605 (2016).

Bartoletti, Massimo, Salvatore Carta, Tiziana Cimoli, and Roberto Saia. "Dissecting Ponzi Schemes on Ethereum: Identification, Analysis, and Impact." (2017).

Bech, Morten, and Rodney Grarratt. "Central Bank Cryptocurrencies." BIS Quarterly Review (2017).

Berentsen, Aleksander, and Fabian Schar. "The Case for Central Bank Electronic Money and the Non-Case for Central Bank Cryptocurrencies." Federal Reserve Bank of St. Louis Review (2018).

Berentsen, Aleksander, and Fabian Schär. "A Short Introduction to the World of Cryptocurrencies." Federal Reserve Bank of St. Louis Review 100, no. 1 (First Quarter 2018): 1-16.

Black, Julia. "Decentring Regulation: The Role of Regulation and Self Regulation in a "Post Regulatory" World." Current Legal Problems 54, no. 1 (2001): 103-46.

Bordo, Michael D, and Andrew T Levin. "Central Bank Digital Currency and the Future of Monetary Policy." National Bureau of Economic Research, 2017.

Brito, Jerry, and Peter van Valkenburgh. "Writing and Publishing Code Alone Cannot Be a Crime." CoinCenter.org (Octover 29, 2018).

Broby, Daniel, and Samuel Baker. "Central Banks and Cryptocurrencies." Centre for Financial Regulation and Innovation - White Paper (2018).

Choo, Kim-Kwang Raymond. "Cryptocurrency and Virtual Currency: Corruption and Money Laundering/Terrorism Financing Risks?". Chap. 15 In Handbook of Digital Currency: Bitcoin, Innovation, Financial Instruments, and Big Data, edited by David Lee Kuo Chuen, 283-307. San Diego, CA: Academic Press, 2015.

Coates IV, John C. "The Volcker Rule as Structural Law: Implications for Cost-Benefit Analysis and Administrative Law." Capital Markets Law Journal 10, no. 4 (2015): 447-68. 
Commission de Surveillance du Secteur Financier (CSSF). "Newsletter No. 157." news release, February 2014, http://www.cssf.lu/fileadmin/files/Publications/Newsletter/Newsletter_2014/newsletter157en g.pdf.

Committee on Payments and Market Infrastructures. "Digital Currencies." Basel: Bank for International Settlements, 2015.

Commodity Futures Trading Commission. "In the Matter Of: Coinflip, Inc., D/B/a Derivabit, and Francisco Riordan, Respondents: Order Instituting Proceedings Pursuant to Sections 6(C) and 6(D) of the Commodity Exchange Act, Making Findings and Imposing Remedial Sanctions (Cftc Docket No. 15-29)." September 17, 2015.

Cooter, Robert. "Prices and Sanctions." Columbia law review 84, no. 6 (1984): 1523-60.

Coppola, Frances. "Lightning Network May Not Solve Bitcoin's Scaling 'Trilemma'." Coindesk, January 20, 2018.

De Filippi, Primavera. "The Interplay between Decentralization and Privacy: The Case of Blockchain Technologies." (2016).

De Filippi, Primavera, and Samer Hassan. "Blockchain Technology as a Regulatory Technology: From Code Is Law to Law Is Code." First Monday 21, no. 12 (2016).

Ehrlich, Isaac, and Richard A. Posner. "An Economic Analysis of Legal Rulemaking." The Journal of Legal Studies 3, no. 1 (1974): 257-86.

Engert, Andreas. "Transnational Hedge Fund Regulation." European Business Organization Law Review 11, no. 03 (2010): 329-78.

European Banking Authority. "Eba Opinion on 'Virtual Currencies'." London: European Banking Authority, 4 July 2014.

"Report with Advice for the European Commission on Crypto-Assets." 9 January 2019.

European Central Bank. The Payment System: Payments, Securities and Derivatives, and the Role of the Eurosystem. Frankfurt am Main: European Central Bank, 2010.

. "The Potential Impact of Dlts on Securities Post-Trading Harmonisation and on the Wider Eu Financial Market Integration." Frankfurt am Main, September 2017.

. "Virtual Currency Schemes." Frankfurt an Main: European Central Bank, October 2012. "Virtual Currency Schemes- a Further Analysis." (February 2015 2015).

European Securities and Markets Authority. "Advice: Initial Coin Offerings and Crypto-Assets." (9 January 2019).

. "The Distributed Ledger Technology Applied to Securities Markets." Paris: European Securities and Markets Authority, 2017.

Financial Conduct Authority. "Guidance on Cryptoassets." Consultation Paper CP19/3 (January 2019).

Financial Stability Board. "Crypto-Asset Markets: Potential Channels for Future Financial Stability Implications." Basel: Financial Stability Board, 10 October 2018.

Financial Stability Oversight Council. "Financial Stability Oversight Council (Fsoc) 2016 Annual Report." Washington, D.C.: Financial Stability Oversight Council, 2016.

Finck, Michèle. Blockchain Regulation and Governance in Europe. Cambridge: Cambridge University Press, 2019.

. "Blockchains: Regulating the Unknown." German Law Journal 19, no. 4 (2018): 665-91.

Finney, Hal. "Re: Bitcoin Bank." December 30, 2010.

Fleischer, Victor. "Regulatory Arbitrage." Texas Law Review 89, no. 2 (2010): 227-89.

Foucault, Michel. Discipline and Punish: The Birth of the Prison. New Yrok: Vintage Books, 1995.

Garcia-de-Andoain, Carlos, Florian Heider, Marie Hoerova, and Simone Manganelli. "Lending-ofLast-Resort Is as Lending-of-Last-Resort Does: Central Bank Liquidity Provision and Interbank Market Functioning in the Euro Area." ECB Working Paper Series No 1886 (2016).

Global Legal Research Directorate Staff of the Library of Congress. "Regulation of Cryptocurrency in Selected Jurisdictions." Washington D.C.,: The Law Library of Congress, June 2018.

Goodhart, Charles. "The Boundary Problem in Financial Regulation." National Institute Economic Review 206, no. 1 (2008): 48-55. 
Goodhart, Charles A. E., and Rosa M. Lastra. "Border Problems." Journal of International Economic Law 13, no. 3 (2010): 705-18.

Griffin, John M, and Amin Shams. "Is Bitcoin Really Un-Tethered?". SSRN Working Paper Series (2018).

Gupta, Sahil, Patrick Lauppe, and Shreyas Ravishankar. "Fedcoin: A Blockchain-Backed Central Bank Cryptocurrency." (2017).

Hart, H. L. A. The Concept of Law. Vol. 2, New York: Oxford University Press, 1994.

Hayek, F. A. "The Use of Knowledge in Society." The American Economic Review 35, no. 4 (1945): 519-30.

He, Dong, Karl Friedrich Habermeier, Ross Leckow, Vikram Haksar, Yasmin Almeida, Mikari Kashima, Nadim Kyriakos-Saad, et al. "Virtual Currencies and Beyond: Initial Considerations." Washington, D.C.: International Monetary Fund, 2016.

He, Dong, Ross Leckow, Vikram Haksar, Tommaso Mancini-Griffoli, Nigel Jenkinson, Mikari Kashima, Tanai Khiaonarong, Céline Rochon, and Hervé Tourpe. "Fintech and Financial Services: Initial Considerations." IMF Staff Discussion Note SDN/17/05 (June 2017 2017).

Jedusor, Tom Elvis "Mimblewimble." (19 July 2016).

Kaplow, Louis. "Rules Versus Standards: An Economic Analysis." Duke Law Journal 42, no. 3 (1992): 557-629.

Kelly, Jemima. "The John Taylor-Backed "Stablecoin" That's Backed by, Um, Stability." Financial Times, June 25, 2018.

Kirzner, Israel M. "The Perils of Regulation: A Market-Process Approach , 119-49.". Chap. 6 In Discovery and the Capitalist Process, edited by Israel M. Kirzner, 119-49. Chicago: University of Chicago Press, 1985.

Koning, JP. "Fedcoin." Moneyness April 11, 2018 (October 19, 2014).

Kroeger, Alexander, and Asani Sarkar. "Is Bitcoin Really Frictionless?" In Federal Reserve Bank of New York Liberty Street Economics. New York: Federal Reserve Bank of New York, 2016.

Kumhof, Michael, and Clare Noone. "Central Bank Digital Currencies — Design Principles and Balance Sheet Implications." Bank of England Staff Working Paper No. 725 (2018).

Lagarde, Christine. "Central Banking and Fintech-a Brave New World?". Bank of England conference, London (September 29, 2017).

Lastra, Rosa Maria, and Jason Grant Allen. "Virtual Currencies in the Eurosystem: Challenges Ahead." Brussels, Belgium: ECON Committee, European Parliament, 2018.

Lessig, Lawrence. Code: And Other Laws of Cyberspace. New York: Basic Books, 1999.

- Code: Version 2.0. New York: Basic Books, 2006. . "The Zones of Cyberspace." Stanford Law Review 48 (1996): 1403-11.

Levin, Simon A., and Andrew W. Lo. "Opinion: A New Approach to Financial Regulation." Proceedings of the National Academy of Sciences 112, no. 41 (2015): 12543-44.

Lo, Andrew W. Adaptive Markets: Financial Evolution at the Speed of Thought. Princeton: Princeton University Press, 2017.

Luther, William J. "Cryptocurrencies, Network Effects, and Switching Costs." Contemporary Economic Policy 34, no. 3 (2016): 553-71.

Luther, William, and Lawrence White. "Can Bitcoin Become a Major Currency?". JMU Working Paper in Economics No. 14-17 (2014).

Mancini-Griffoli, Tommaso, Maria Soledad Martinez, Itai Agur Peria, Anil Ari, John Kiff, Adina Popescu, and Celine Rochon. "Casting Light on Central Bank Digital Currency." IMF Staff Discussion Note No. 18/08 (2018).

Maupin, Julie. "Mapping the Global Legal Landscape of Blockchain and Other Distributed Ledger Technologies." Centre for International Governance Innovation Papaers No. 149 (2017).

Mersch, Yves. "Digital Base Money: An Assessment from the Ecb's Perspective." In Speech at the Farewell ceremony for Pentti Hakkarainen, Deputy Governor of Suomen Pankki - Finlands Bank, Helsinki, 16 January 2017.

"Virtual Currencies Ante Portas." Speech at the 39th meeting of the Governor's Club Bodrum, Turkey, 14 May 2018 (14 May 2018).

Mills, David, Kathy Wang, Brendan Malone, Anjana Ravi, Jeffrey Marquardt, Clinton Chen, Anton Badev, et al. "Distributed Ledger Technology in Payments, Clearing, and Settlement." 
Finance and Economics Discussion Series Divisions of Research \& Statistics and Monetary Affairs, Federal Reserve Board (2016).

Morgan, Bronwen, and Karen Yeung. An Introduction to Law and Regulation: Texts and Materials. New York: Cambridge University Press, 2007.

Nabilou, Hossein. "Bank Proprietary Trading and Investment in Private Funds: Is the Volcker Rule a Panacea or yet Another Maginot Line?". Banking and Finance Law Review 32, no. 2 (2017): 297-341.

. "Central Bank Digital Currencies: Preliminary Legal Observations." SSRN Working Paper Series (2019).

. "The Dark Side of Licensing Cryptocurrency Exchanges as Payment Institutions." SSRN Working Paper Series (2019).

. "Regulatory Arbitrage and Hedge Fund Regulation: The Need for a Transnational Response." Fordham Journal of Corporate and Financial Law 22, no. 4 (2017): 557-603.

Nabilou, Hossein, and Alessio M. Pacces. "The Hedge Fund Regulation Dilemma: Direct Vs. Indirect Regulation." William \& Mary Business Law Review 6, no. I (2015).

Nabilou, Hossein, and André Prüm. "Ignorance, Debt and Cryptocurrencies: The Old and the New in the Law and Economics of Concurrent Currencies." Journal of Financial Regulation 5, no. 1 (2019): 1-35.

Nair, Malavika, and Nicolás Cachanosky. "Bitcoin and Entrepreneurship: Breaking the Network Effect." The Review of Austrian Economics 30, no. 3 (September 01 2017): 263-75.

Nakamoto, Satoshi. "Bitcoin: A Peer-to-Peer Electronic Cash System." 2008.

Office of the New York State Attorney General. "Virtual Markets Integrity Initiative Report." September 18, 2018.

Payne, Jennifer. "The Role of Gatekeepers." Chap. 9 In The Oxford Handbook of Financial Regulation, edited by Niamh Moloney, Eilís Ferran and Jennifer Payne, 254-79. Oxford: Oxford University Press, 2015.

Pieters, Gina C. "The Potential Impact of Decentralized Virtual Currency on Monetary Policy." Federal Reserve Bank of Dallas Globalization and Monetary Policy Institute 2016 Annual Report (2017): 20-25.

Pinna, Andrea, and Wiebe Ruttenberg. "Distributed Ledger Technologies in Securities Post-Trading: Revolution or Evolution?". ECB Occasional Paper Series No 172 (April 2016 2016).

Poon, Joseph, and Thaddeus Dryja. "The Bitcoin Lightning Network: Scalable Off-Chain Instant Payments." (2016).

Popper, Nathaniel. "Goldman Sachs to Open a Bitcoin Trading Operation." The New York Times, May 2, 2018.

Prasad, Eswar. "Central Banking in a Digital Age: Stock-Taking and Preliminary Thoughts." Hutchins Center on Fiscal \& Monetary Policy at Brookings (April 2018).

Ricks, Morgan. "Money as Infrastructure." Vanderbilt Law Research Paper No. 17-63 (2018).

Rizzo, Pete. "New York Regulators Grant Second Bitlicense to Ripple." Coindesk (June 13, 2016).

Schaefer, Hans-Bernd. "Legal Rule and Standards." In The Encyclopedia of Public Choice, Volume I, edited by Charles K. Rowley and Friedrich Schneider, 347-50. New York: Kluwer Academic Publishers, 2004.

Schär, Fabian, and Aleksander Berentsen. "Stablecoins: The Quest for a Low-Volatility Cryptocurrency." In The Economics of Fintech and Digital Currencies, edited by Antonio Fatás. London: CEPR Presss, 2019.

Schiltz, Jean-Louis, and Nadia Manzari. "The Virtual Currency Regulation Review: Luxembourg." The Law Reviews (2018).

Schlag, Pierre. "Rules and Standards." UCLA Law Review 33 (1985): 379-430.

Schooner, Heidi Mandanis, and Michael W. Taylor. Regulation of Global Banking: Principles and Policies. Academic Press, 2010.

Scott, Colin. "Accountability in the Regulatory State." Journal of Law and Society 27, no. 1 (2000): $38-60$.

"Regulation in the Age of Governance: The Rise of the Post-Regulatory State." In The Politics of Regulation: Institutions and Regulatory Reforms for the Age of Governance, edited 
by Jacint Jordana and David Levi-Faur, 145-74. Northampton, Massachusetts: Edward Elgar Publishing, Inc., 2004.

Securities and Exchange Commission. "Report of Investigation Pursuant to Section 21(a) of the Securities Exchange Act of 1934: The Dao." Washington, DC, July 25, 2017.

Shin, Laura. "Will This Battle for the Soul of Bitcoin Destroy It?" Forbes, Oct. 23, 2017.

Song, Jimmy. "Bits Denomination Bip." GitHub, https://github.com/bitcoin/bips/blob/master/bip0176.mediawiki.

Stokes, Robert. "Virtual Money Laundering: The Case of Bitcoin and the Linden Dollar." Information \& Communications Technology Law 21, no. 3 (2012/10/01 2012): 221-36.

Sunstein, Cass R. "Problems with Rules." California Law Review 83, no. 4 (1995): 953-1026.

Taylor, M. "Institutional Structures of Regulation." Chap. 45 In Handbook of Safeguarding Global Financial Stability: Political, Social, Cultural, and Economic Theories and Models, edited by Gerard Caprio Jr., 473-80. London: Elsevier Inc., 2013.

The Department of the, Treasury. "Blueprint for a Modernized Financial Regulatory Structure." 2008.

The Group of Thirty, Working Group on Financial Supervision. "The Structure of Financial Supervision: Approaches and Challenges in a Global Marketplace." Washington, DC, 2008.

Van Steenis, Huw, Betsy L. Graseck, Fiona Simpson, and James E. Faucette. "Global Insight: Blockchain in Banking: Disruptive Threat or Tool?" In Morgan Stanley Research Report. New York: Morgan Stanely, 2016.

van Wirdum, Aaron "A Primer on Bitcoin Governance, or Why Developers Aren't in Charge of the Protocol." Bitcoin Magazine, Sept. 7, 2016.

. "A Primer on Bitcoin Governance, or Why Developers Aren't in Charge of the Protocol." BITCOINMAGAZINE, Sept. 7, 2016.

. "The History of Lightning: From Brainstorm to Beta." Bitcoin Magazine (4 April 2018).

. "Mimblewimble: How a Stripped-Down Version of Bitcoin Could Improve Privacy, Fungibility and Scalability All at Once." Bitcoin Magazine (12 August 2016).

Walch, Angela. "In Code(Rs) We Trust: Software Developers as Fiduciaries in Public Blockchains." In Regulating Blockchain: Techno-Social and Legal Challenges, edited by Philipp Hacker, Ioannis Lianos, Georgios Dimitropoulos and Stefan Eich. Oxford: Oxford University Press, Forthcoming 2019.

White, Larry. "The World's First Central Bank Electronic Money Has Come - and Gone: Ecuador, 2014-2018." Alt-M: Ideas for an Alternative Monetary Future (March 29, 2018).

Yeoh, Peter. "Regulatory Issues in Blockchain Technology." Journal of Financial Regulation and Compliance 25, no. 2 (2017): 196-208.

Yeung, Karen. "Towards an Understanding of Regulation by Design." In Regulating Technologies: Legal Futures, Regulatory Frames and Technological Fixes, edited by Roger Brownsword and Karen Yeung, 79-107. Portland, Oregon: Hart Publishing, 2008.

Zetzsche, Dirk A, Ross P Buckley, and Douglas W Arner. "The Distributed Liability of Distributed Ledgers: Legal Risks of Blockchain." University of Illinois Law Review (forthcoming) (2017). 